\title{
Multifunctional Phytocompounds in Cotoneaster Fruits: Phytochemical Profiling, Cellular Safety, Anti-Inflammatory and Antioxidant Effects in Chemical and Human Plasma Models In Vitro
}

\author{
Agnieszka Kicel $\mathbb{D}^{1},{ }^{1}$ Joanna Kolodziejczyk-Czepas, ${ }^{2}$ Aleksandra Owczarek, \\ Magdalena Rutkowska, ${ }_{1}$ Anna Wajs-Bonikowska, ${ }^{3}$ Sebastian Granica, ${ }^{4}$ Pawel Nowak, ${ }^{2}$ \\ and Monika A. Olszewska $\mathbb{D}^{1}$ \\ ${ }^{1}$ Department of Pharmacognosy, Faculty of Pharmacy, Medical University of Lodz, 1 Muszynskiego, 90-151 Lodz, Poland \\ ${ }^{2}$ Department of General Biochemistry, Faculty of Biology and Environmental Protection, University of Lodz, Pomorska 141/143, \\ 90-236 Lodz, Poland \\ ${ }^{3}$ Institute of General Food Chemistry, Faculty of Biotechnology and Food Sciences, Lodz University of Technology, 4/ \\ 10 Stefanowskiego, 90-924 Lodz, Poland \\ ${ }^{4}$ Department of Pharmacognosy and Molecular Basis of Phytotherapy, Faculty of Pharmacy, Medical University of Warsaw, \\ 1 Banacha, 02-097 Warsaw, Poland
}

Correspondence should be addressed to Agnieszka Kicel; agnieszka.kicel@umed.lodz.pl

Received 22 June 2018; Accepted 30 August 2018; Published 24 October 2018

Academic Editor: Felipe L. de Oliveira

Copyright (C) 2018 Agnieszka Kicel et al. This is an open access article distributed under the Creative Commons Attribution License, which permits unrestricted use, distribution, and reproduction in any medium, provided the original work is properly cited.

The work presents the results of an investigation into the molecular background of the activity of Cotoneaster fruits, providing a detailed description of their phytochemical composition and some of the mechanisms of their anti-inflammatory and antioxidant effects. GS-FID-MS and UHPLC-PDA-ESI-MS ${ }^{3}$ methods were applied to identify the potentially health-beneficial constituents of lipophilic and hydrophilic fractions, leading to the identification of fourteen unsaturated fatty acids (with dominant linoleic acid, 375.4-1690.2 $\mathrm{mg} / 100 \mathrm{gdw}$ ), three phytosterols (with dominant $\beta$-sitosterol, $132.2-463.3 \mathrm{mg} / 100 \mathrm{~g}$ ), two triterpenoid acids $(10.9-54.5 \mathrm{mg} / 100 \mathrm{~g})$, and twenty-six polyphenols $(26.0-43.5 \mathrm{mg} \mathrm{GAE} / \mathrm{g} \mathrm{dw})$. The most promising polyphenolic fractions exhibited dose-dependent anti-inflammatory activity in in vitro tests of lipoxygenase $\left(\mathrm{IC}_{50}\right.$ in the range of $\left.7.7-24.9 \mu \mathrm{g} / \mathrm{U}\right)$ and hyaluronidase $\left(\mathrm{IC}_{50}\right.$ in the range of $16.4-29.3 \mu \mathrm{g} / \mathrm{U}$ ) inhibition. They were also demonstrated to be a source of effective antioxidants, both in in vitro chemical tests (DPPH, FRAP, and TBARS) and in a biological model, in which at in vivo-relevant levels $(1-5 \mu \mathrm{g} / \mathrm{mL})$ they normalized/enhanced the nonenzymatic antioxidant capacity of human plasma and efficiently protected protein and lipid components of plasma against peroxynitrite-induced oxidative/nitrative damage. Moreover, the investigated extracts did not exhibit cytotoxicity towards human PMBCs. Among the nine Cotoneaster species tested, C. hjelmqvistii, C. zabelii, C. splendens, and C. bullatus possess the highest bioactive potential and might be recommended as dietary and functional food products.

\section{Introduction}

Edible fruits are widely recognized as a valuable source of structurally diverse phytochemicals with a broad spectrum of health-promoting properties. Decreased cholesterol levels, lower blood pressure, better mental health, and protection against cancer are only a few of the many benefits associated with the regular intake of fruit products, as indicated by numerous epidemiological studies [1]. Among the different fruit-bearing families, the Rosaceae seems to be of special importance. With over 3000 species, the family provides numerous types and varieties of fruits, some of which, such 


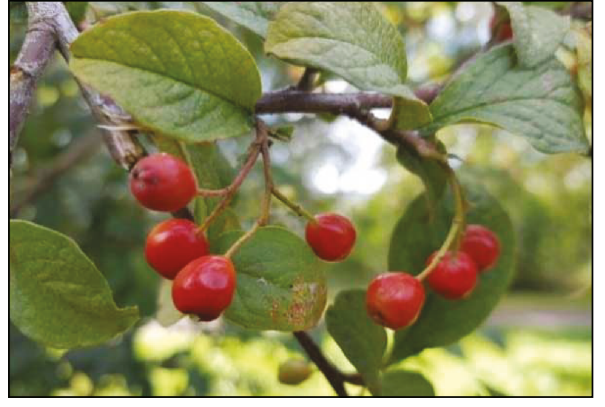

(a)

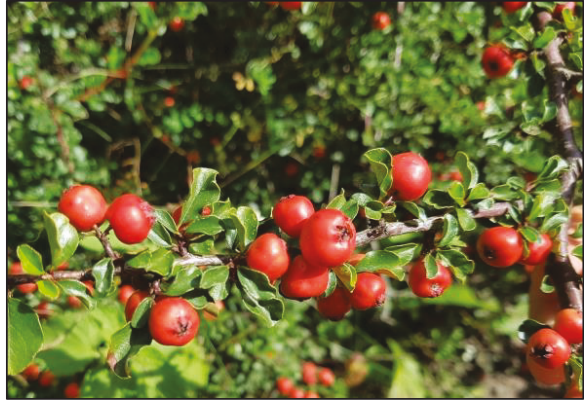

(b)

Figure 1: The fruits of C. bullatus (a) and C. splendens (b).

as apples, pears, strawberries and cherries, have great economic and dietary importance, and are frequently and willingly consumed due to their excellent flavors and proven nutritional value [2]. Many other taxa (e.g., Aronia sp., Sorbus sp., Pyracantha sp., and Prunus spinosa L.) produce fruits, that while less attractive in taste and appearance, are, nonetheless, distinguished by especially high quantities of bioactive constituents, which makes them perfect candidates for more specialized food applications, for example, as functional food products or food additives [3-6].

The chemical diversity of health-beneficial phytochemicals contained in rosaceous plant materials is immense and ranges from highly lipophilic to strongly polar constituents. Unsaturated fatty acids of almond oil, the cholesterolregulating phytosterols of Prunus africana (Hook.f.) Kalkman, and the pentacyclic triterpenes, ubiquitous throughout the Rosaceae, with proven anti-inflammatory activity are some examples of the possible structures from the hydrophobic end of the spectrum $[7,8]$. On the other hand, the hydrophilic fractions often contain an abundance of highly-valued polyphenol antioxidants belonging to numerous chemical classes, such as flavonoids, phenolic acids, and tannins. The bioactive potential of Rosaceae fruits is, therefore, associated not with a single fraction but rather is an effect of the presence of a range of phytochemicals.

The genus Cotoneaster Medikus is one of the largest genera of the Rosaceae family (subfamily Spiraeoideae, tribe Pyreae) comprising about 500 species of shrubs or small trees. Its members are native to the Palearctic region (temperate Asia, Europe, north Africa) but are often cultivated throughout Europe as ornamental plants due to their decorative bright red fruits (Figure 1). The center of diversity of the taxon are the mountains of southwestern China and the Himalayas $[9,10]$, where the fruits have been used for culinary purposes by the local communities. The nutritional value of the fruits as a source of vitamins and minerals has been confirmed $[11,12]$ and additional beneficial health effects of the fruit consumption have been also reported in the traditional medicine for the treatment of diabetes mellitus, cardiovascular diseases, nasal hemorrhage, excessive menstruation, fever, and cough $[9,10]$. The phytochemical research on the subject is scarce, but the available data indicate the tendency of the fruits to accumulate a wide range of active metabolites. In particular, the fruits of Cotoneaster pannosus Franch. are a source of linoleic acid, those of
Cotoneaster microphylla Wall ex Lindl contain pentacyclic triterpenoids, and the polyphenolic fractions of C. pannosus and Cotoneaster integerrimus Medik. fruits are rich in epicatechin, shikimic acid, and chlorogenic acid [9, 11, 12]. However, broader generalization of their properties is troublesome, and the possible wider application of the fruits, for example, as functional food products, is hindered by a lack of systematic studies. Similarly limited is the information on the activity of Cotoneaster fruits. Preliminary studies have been performed on the fruits of $C$. integerrimus and C. pannosus with regard to their antioxidant, anticholinesterase, antityrosinase, antiamylase, and antiglucosidase properties, and their free radical-scavenging potential was proven to be the most promising $[9,12]$. Still, the research was carried out using only simple in vitro chemical tests and did not cover in vivo-relevant antioxidant mechanisms.

The aim of this study was, therefore, to provide a more detailed insight into the chemical composition and activity of Cotoneaster fruits. To this end, the fruits from nine species of Cotoneaster cultivated in Poland were analyzed for a range of lipophilic and hydrophilic (polyphenolic) constituents with acknowledged health-promoting properties using a combination of chromatographic and spectroscopic methods (GC-FID-MS, UHPLC-PDA-ESI-MS ${ }^{3}$, and UV-Vis spectrophotometry). The most promising polyphenolic fractions were then subjected to an analysis of antioxidant activity comprising eight complementary in vitro tests (both chemical and biological plasma models) covering some of the mechanisms crucial for reducing the level of oxidative damage in the human organism, that is, scavenging of free radicals, enhancement of the nonenzymatic antioxidant capacity of blood plasma, and protection of its lipid and protein components against oxidative/nitrative changes. Additionally, the inhibitory effects of the fruit extracts on the proinflammatory enzymes, that is, lipoxygenase and hyaluronidase, were also measured. Finally, the cellular safety of the extracts was evaluated in cytotoxicity tests employing human peripheral blood mononuclear cells (PMBCs).

\section{Materials and Methods}

2.1. Plant Material. The fruit samples of nine selected Cotoneaster Medik. species, that is, C. lucidus Schltdl. (AR), C. divaricatus Rehder et E.H. Wilson (BG), C. horizontalis Decne. (BG), C. nanshan Mottet (BG), C. hjelmqvistii Flinck 
et B. Hylmö (BG), C. dielsianus E. Pritz. (BG), C. splendens Flinck et B. Hylmö (BG), C. bullatus Bois (BG), and C. zabelii C.K. Schneid. (BG) were collected in September 2013, in the Botanical Garden (BG; $51^{\circ} 45^{\prime} \mathrm{N} 19^{\circ} 24^{\prime} \mathrm{E}$ ) in Lodz (Poland) and in the Arboretum (AR; $51^{\circ} 49^{\prime} \mathrm{N} 19^{\circ} 53^{\prime} \mathrm{E}$ ), Forestry Experimental Station of Warsaw University of Life Sciences (SGGW) in Rogow (Poland). The voucher specimens were deposited in the Herbarium of the Department of Pharmacognosy, Medical University of Lodz (Poland). The raw materials were powdered with an electric grinder, sieved through a $0.315 \mathrm{~mm}$ sieve, and stored in airtight containers until use.

2.2. General. Reagents and standards of analytical or HPLC grade such as 2,2-diphenyl-1-picrylhydrazyl (DPPH), 2,4,6-tris-(2-pyridyl)-s-triazine (TPTZ), 2,2' -azobis-(2amidinopropane)-dihydrochloride (AAPH), linoleic acid, 2-thiobarbituric acid, Tween ${ }^{\circledR}$ 40, 5, $5^{\prime}$-dithiobis-(2-nitrobenzoic acid) (DNTB), xylenol orange disodium salt, Histopaque $^{\circledR}$ - 1077 medium N,O-bis-(trimethylsilyl)-trifluoroacetamide with 1\% 1-trimethylchlorosilane (BSTFA + TMCS), boron trifluoride, bovine testis hyaluronidase, lipoxygenase from soybean, reference standards of fatty acid methyl esters (FAMEs), ethyl oleate, 5 - $\alpha$-cholesterol, ( \pm )-6hydroxy-2,5,7,8-tetramethylchromane-2-carboxylic acid $\left(\right.$ Trolox $\left.{ }^{\circledR}\right)$, butylated hydroxyanisole (BHA), 2,6-di-tertbutyl-4-methylphenol (BHT), gallic acid monohydrate, quercetin dehydrate, chlorogenic acid hemihydrate (5-Ocaffeoylquinic acid), 3-O- and 4-O-caffeoylquinic acids, hyperoside semihydrate, isoquercitrin, rutin trihydrate, procyanidins B-2 and C-1, (-)-epicatechin, and indomethacin were purchased from Sigma-Aldrich (St. Louis, MO, USA). The standards of quercetin 3-O- $\beta$-D-(2" $-O-\beta$-D-xylosyl)galactoside and quercitrin (quercetin 3-O- $\alpha$-L-rhamnoside) have previously been isolated in our laboratory from $C$. bullatus and C. zabelii leaves with at least 95\% HPLC purity (unpublished results). $\mathrm{A}\left(\mathrm{Ca}^{2+}\right.$ and $\left.\mathrm{Mg}^{2+}\right)$-free phosphate buffered saline (PBS) was purchased from Biomed (Lublin, Poland). Peroxynitrite was synthesized according to Pryor et al. [13]. Anti-3-nitrotyrosine polyclonal antibody, biotinconjugated secondary antibody, and streptavidin/HRP were purchased from Abcam (Cambridge, UK). HPLC grade solvents such as acetonitrile and formic acid were from Avantor Performance Materials (Gliwice, Poland). For chemical tests, the samples were incubated at a constant temperature using a BD 23 incubator (BINDER, Tuttlingen, Germany) and measured using a UV-1601 Rayleigh spectrophotometer (Beijing, China). Activity tests in blood plasma models and enzyme inhibitory assays were performed using 96-well plates and monitored using a SPECTROStar Nano microplate reader (BMG LABTECH, Ortenberg, Germany).

\subsection{Phytochemical Profiling}

2.3.1. Extraction and Derivatization of Lipophilic Phytochemicals. The fruit samples $(7.0 \mathrm{~g})$ were exhaustively extracted in a Soxhlet apparatus with chloroform $(150 \mathrm{~mL}$, $24 \mathrm{~h}$ ), to give lipid extracts $(288-467 \mathrm{mg} \mathrm{dw})$, which were then subjected to quantification of lipophilic compounds.
Fatty acids were assayed as fatty acid methyl esters (FAMEs) prepared according to a method described earlier [14]. Phytosterols and triterpenes were assayed after their transformation to trimethylsilyl ethers (TMSs) according to Thanh et al. [15]. The FAME and TMS mixtures were independently analyzed by GC-FID-MS.

2.3.2. GC-FID-MS Analysis. The analyses of lipophilic fractions were performed on a Trace GC Ultra instrument coupled with a DSQII mass spectrometer (Thermo Electron, Waltham, MA, USA) and a MS-FID splitter (SGE Analytical Science, Trajan Scientific Americas, Austin, TX, USA). The applied mass range was 33-550 amu, ion source-heating was $200^{\circ} \mathrm{C}$, and ionization energy was $70 \mathrm{eV}$. The conditions for FAMEs were as follows: capillary column: TG-WaxMS $(30 \mathrm{~m} \times 0.25 \mathrm{~mm}$ i.d., film thickness $0.25 \mu \mathrm{m}$; Thermo Fisher Scientific, Waltham, MA, USA); temperature program: 3-30 min: $50-240^{\circ} \mathrm{C}$ at $4^{\circ} \mathrm{C} / \mathrm{min}$; and injector and detector temperatures: $250^{\circ} \mathrm{C}$ and $260^{\circ} \mathrm{C}$, respectively. The conditions for TMSs were as follows: capillary column: HP-5 $(30 \mathrm{~m} \times 0.25 \mathrm{~mm}$ i.d., film thickness $0.25 \mu \mathrm{m}$; Agilent Technologies, Santa Clara, CA, USA); temperature program: $1-15 \mathrm{~min}: 100-250^{\circ} \mathrm{C}$, at $10^{\circ} \mathrm{C} / \mathrm{min} ; 15-30 \mathrm{~min}: 250-300^{\circ} \mathrm{C}$, at $4^{\circ} \mathrm{C} / \mathrm{min}$; and injector and detector temperatures: $310^{\circ} \mathrm{C}$ and $300^{\circ} \mathrm{C}$, respectively. In all cases, the carrier gas was helium (constant pressure: $300 \mathrm{kPa}$ ). The lipophilic analytes were identified by comparison of their MS profiles with those stored in the libraries NIST 2012 and Wiley Registry of Mass Spectral Data (10th and 11th eds). Retention times $\left(t_{R}\right)$ of FAMEs were also compared with those of the commercial FAME mixture. The analyte levels were expressed as $\mathrm{mg} / 100 \mathrm{~g}$ fruit dry weight $(\mathrm{dw})$, calculated using the internal standards of ethyl oleate and 5- $\alpha$-cholesterol (for the fatty acids as well as phytosterols and triterpenoids, respectively) and it was recalculated to the content in the plant material taking into account the extraction yield.

2.3.3. Extraction of Polyphenolic Compounds. The fruit samples $(100-500 \mathrm{mg})$ were first defatted by preextraction with chloroform $(20 \mathrm{~mL}, 15 \mathrm{~min}$; the chloroform extracts were discarded), then refluxed for $30 \mathrm{~min}$ with $30 \mathrm{~mL}$ of $70 \%(v / v)$ aqueous methanol, and twice for $15 \mathrm{~min}$ with $20 \mathrm{~mL}$ of the same solvent. The combined extracts were diluted with the extractant to $100 \mathrm{~mL}$. Each sample was extracted in triplicate to give the test extracts, which were analyzed for their total phenolic contents (TPCs) and antioxidant activity in chemical models. For UHPLC analyses and antioxidant activity evaluation in the human plasma models, the test extracts were evaporated in vacuo and lyophilized using an Alpha 1-2/LDplus freeze dryer (Christ, Osterode am Harz, Germany) before weighing.

2.3.4. UHPLC-PDA-ESI-MS $S^{3}$ Analysis. Metabolite profiling was performed on an UltiMate 3000 RS UHPLC system (Dionex, Dreieich, Germany) with PDA detector scanning in the wavelength range of $220-450 \mathrm{~nm}$ and an amaZon SL ion trap mass spectrometer with ESI interface (Bruker Daltonics, Bremen, Germany). Separations were carried out on a Kinetex XB-C18 column $(150 \times 2.1 \mathrm{~mm}, 1.7 \mu \mathrm{m}$; 
Phenomenex Inc., Torrance, CA, USA). The mobile phase consisted of solvent A (water-formic acid, 100:0.1, v/v) and solvent B (acetonitrile-formic acid, 100:0.1, v/v) with the following elution profile: $0-45 \mathrm{~min}, 6-26 \%(v / v) \mathrm{B}$; 45-55 min, 26-95\% B; 55-60 $\mathrm{min}, 95 \% \mathrm{~B}$; and 60-63 min, $95-6 \%$ B. The flow rate was $0.3 \mathrm{~mL} / \mathrm{min}$. The column temperature was $25^{\circ} \mathrm{C}$. Before injections, samples of dry extracts $(15 \mathrm{mg})$ were dissolved in $1.5 \mathrm{~mL}$ of $70 \%$ aqueous methanol, filtered through PTFE syringe filters $(25 \mathrm{~mm}$, $0.2 \mu \mathrm{m}$, Vitrum, Czech Republic) and injected ( $3 \mu \mathrm{L})$ into the UHPLC system. UV-Vis spectra were recorded over a range of $200-600 \mathrm{~nm}$, and chromatograms were acquired at 280,325 , and $350 \mathrm{~nm}$. The LC eluate was introduced directly into the ESI interface without splitting and analyzed in a negative ion mode using a scan from $\mathrm{m} / z 70$ to 2200 . The $\mathrm{MS}^{2}$ and $\mathrm{MS}^{3}$ fragmentations were obtained in Auto MS/MS mode for the most abundant ions at the time. The nebulizer pressure was $40 \mathrm{psi}$, dry gas flow was $9 \mathrm{~L} / \mathrm{min}$, dry temperature was $300^{\circ} \mathrm{C}$, and capillary voltage was $4.5 \mathrm{kV}$.

2.3.5. Determination of Total Phenolic Content (TPC). The TPC levels were determined according to the FolinCiocalteu method as described previously [16]. The results were expressed as mg of gallic acid equivalents (GAE) per $g$ of dry weight of the plant material (mg GAE/g dw).

2.4. Lipoxygenase (LOX) and Hyaluronidase (HYAL) Inhibition Tests. The ability of the fruit extracts to inhibit lipoxygenase (LOX) and hyaluronidase (HYAL) was evaluated according to the method optimized earlier [17]. The results of both tests were expressed as $\mathrm{IC}_{50}$ values $(\mu \mathrm{g} / \mathrm{mL})$ from concentration-inhibition curves.

2.5. Antioxidant Activity in Chemical Models. The DPPH free-radical scavenging activity was determined according to a previously optimized method [16] and expressed as normalized $\mathrm{EC}_{50}$ values calculated from concentrationinhibition curves. The FRAP (ferric reducing antioxidant power) was determined according to [16] and expressed in $\mu \mathrm{mol}$ of ferrous ions $\left(\mathrm{Fe}^{2+}\right)$ produced by $1 \mathrm{~g}$ of the dry extract or standard, which was calculated from the calibration curve of ferrous sulfate. The ability of the extracts to inhibit AAPHinduced peroxidation of linoleic acid was assayed as described previously [18] with peroxidation monitored by quantification of thiobarbituric acid-reactive substances (TBARS) according to a previously optimized method [19], and the antioxidant activity was expressed as $\mathrm{IC}_{50}$ values calculated from concentration-inhibition curves. Additionally, the activity parameters in all of the assays were also expressed as $\mu \mathrm{mol}$ Trolox ${ }^{\circledR}$ equivalents (TE) per $g$ of dry weight of the plant material $(\mu \mathrm{mol} \mathrm{TE} / \mathrm{gdw})$.

\subsection{Antioxidant Activity in Human Plasma Models}

2.6.1. Isolation of Blood Plasma and Sample Preparation. Blood (buffy coat units) from eight healthy volunteers, received from the Regional Centre of Blood Donation and Blood Treatment in Lodz (Poland), was centrifuged to obtain plasma [20]. All experiments were approved by the committee on the Ethics of Research at the Medical University of
Lodz RNN/347/17/KE. Plasma samples, diluted with $0.01 \mathrm{M}$ Tris/HCl pH $7.4(1: 4 v / v)$, were preincubated for $15 \mathrm{~min}$ at $37^{\circ} \mathrm{C}$ with the examined extracts, added to the final concentration range of $1-50 \mu \mathrm{g} / \mathrm{mL}$, and then exposed to 100 or $150 \mu \mathrm{M}$ peroxynitrite $\left(\mathrm{ONOO}^{-}\right)$. Control samples were prepared with plasma untreated with the extracts and/or peroxynitrite. To eliminate the possibility of direct interactions of the extracts with plasma proteins and lipids, several experiments with blood plasma and the extracts only (without adding $\mathrm{ONOO}^{-}$) were also performed and no prooxidative effect was found.

2.6.2. Determination of 3-Nitrotyrosine and Thiols in Human Plasma Proteins. The peroxynitrite-induced protein damage in blood plasma was determined by the use of 3 -nitrotyrosine and protein thiol levels $(-\mathrm{SH})$ as biomarkers of oxidative stress. Immunodetection of 3-nitrotyrosinecontaining proteins by the competitive ELISA (C-ELISA) method in plasma samples (control or antioxidants and $100 \mu \mathrm{M} \mathrm{ONOO}^{-}$-treated plasma) was performed according to [20]. The nitrofibrinogen (3NT-Fg, at a concentration of $0.5 \mu \mathrm{g} / \mathrm{mL}$ and 3-6 mol nitrotyrosine/mol protein) was prepared for use in the standard curve. The concentrations of nitrated proteins that inhibit antinitrotyrosine antibody binding were estimated from the standard curve and are expressed as the 3NT-Fg equivalents (in $\mathrm{nmol} / \mathrm{mg}$ of plasma protein). The concentration of free thiol groups $(-\mathrm{SH})$ in plasma samples (control or antioxidants and $100 \mu \mathrm{M} \mathrm{ONOO}^{-}$-treated plasma) was measured spectrophotometrically according to Ellman's method [20]. The free thiol group concentration was calculated from the standard curve of glutathione (GSH) and expressed as umol/mL of plasma.

2.6.3. Determination of Lipid Hydroperoxides and TBARS in Human Blood Plasma. The peroxynitrite-induced lipid peroxidation in blood plasma was determined spectrophotometrically by evaluation of the level of lipid hydroperoxides and TBARS. The concentration of hydroperoxides in plasma samples (control or antioxidants and $100 \mu \mathrm{M} \mathrm{ONOO}^{-}$treated plasma) was determined by a ferric-xylenol orange (FOX-1) protocol with a later modification [20]. The amount of lipid hydroperoxides was calculated from the standard curve of hydrogen peroxide and expressed in nmol/mg of plasma proteins. Determination of TBARS in plasma samples (control or antioxidants and $100 \mu \mathrm{M} \mathrm{ONOO}^{-}$-treated plasma) was performed according to [20]. The TBARS values were expressed in $\mu \mathrm{mol}$ TBARS $/ \mathrm{mL}$ of plasma.

2.6.4. Ferric Reducing Ability of Human Blood Plasma (FRAP). The influence of the extracts on the nonenzymatic antioxidant status of plasma was conducted by measurements of their ability to reduce ferric ions $\left(\mathrm{Fe}^{3+}\right)$ to ferrous ions $\left(\mathrm{Fe}^{2+}\right)$. The experiments were performed according to Benzie and Strain [21] and modified by KolodziejczykCzepas et al. [20]. The FRAP values of plasma samples (control or antioxidants and $150 \mu \mathrm{M} \mathrm{ONOO}^{-}$-treated plasma) were expressed in $\mathrm{mM} \mathrm{Fe}^{2+}$ in plasma as calculated from the calibration curve of ferrous sulphate. 
2.7. Cellular Safety Testing. The cytotoxicity of the examined extracts was conducted in an experimental system of peripheral blood mononuclear cells (PBMCs). PBMCs were isolated from fresh human blood using the Histopaque ${ }^{\circledR}-1077$ medium, according to a procedure described in our previous work [19]. Then, the cells $\left(1 \times 10^{6} \mathrm{PBMCs} / \mathrm{mL}\right.$, suspended in PBS) were incubated with Cotoneaster fruit extracts at the final concentrations of 5,25 , and $50 \mu \mathrm{g} / \mathrm{mL}$. Measurements of cell viability were executed after two, four, and six hours of incubation $\left(\right.$ at $37^{\circ} \mathrm{C}$ ) in a routine dye excluding test, based on a staining with $0.4 \%$ Trypan blue. The procedure was carried out according to the manufacturer's protocol using a microchip-type automatic cell counter Bio-Rad (Hercules, CA, USA).

2.8. Statistical and Data Analysis. The statistical analysis was performed using STATISTICA 13Pl software for Windows (StatSoft Inc., Krakow, Poland). The results were reported as means \pm standard deviation (SD) or \pm standard error (SE) for the indicated number of experiments. The significance of differences between the samples and controls were analyzed by one-way ANOVA, followed by the post hoc Tukey's test for multiple comparison. A level of $p<0.05$ was accepted as statistically significant.

\section{Results and Discussion}

3.1. GC-FID-MS Analysis of Fatty Acids. The fatty acid profiles of the lipophilic fractions in the chloroform extracts of the Cotoneaster fruits were determined by GC-FID-MS analysis of methyl ester derivatives (FAMEs). As shown in Table 1 and Figure 2, fourteen fatty acids were identified, including saturated, mono-, and polyunsaturated acids with chain lengths ranging from 6 to 22 carbon atoms. Their total content (TFA) varied among the Cotoneaster species from 902.5 to $2683.8 \mathrm{mg} / 100 \mathrm{~g}$ of fruit dry weight $(\mathrm{dw})$ with the highest levels noted for C. zabelii $(2683.8 \mathrm{mg} / 100 \mathrm{~g} \mathrm{dw})$ and C. splendens $(2024.1 \mathrm{mg} / 100 \mathrm{gdw})$. All analyzed fruits contained primarily poly- and monounsaturated acids, constituting $41.6-66.8 \%$ and $18.6-29.6 \%$ of TFA, respectively. The major component in each sample was linoleic acid C18:2 $\Delta^{9,12}$, the sole representative of the polyunsaturated acids. Its content varied among species from 375.4 to $1690.2 \mathrm{mg} / 100 \mathrm{~g}$ fruit $\mathrm{dw}$ with the highest amounts (above $10 \mathrm{mg} / \mathrm{g} \mathrm{dw}$ ) recorded for the fruits of C. zabelii, C. splendens, C. hjelmqvistii, and C. horizontalis. Relatively high levels of oleic acid C18:1 $\Delta^{9}$, a monounsaturated acid, were also noted, especially for the C. zabelii and C. splendens (649.7 and $473.7 \mathrm{mg} / 100 \mathrm{gdw}$, respectively). Regarding saturated acids, they accounted for only $12.3-28.8 \%$ of TFA. The highest content of this group was observed in the fruits of C. zabelii, C. splendens, and C. nanshan, with palmitic acid C16:0 being the dominant compound (226.5, 212.6 and $168.7 \mathrm{mg} / 100 \mathrm{gdw}$, respectively).

The present work is the first comparison of several Cotoneaster fruits in terms of their fatty acid profile. Despite some quantitative differences observed between the investigated fruits, a high level of consistency can be noticed in the qualitative composition of this fraction. The results are in accordance with previous reports for the fruits of C. pannosus from Italy, as well as the branches of C. horizontalis Decke. of Egyptian origin and the seeds of C. bullatus, C. dielsianus, C. francheti Bois, C. moupinensis Franch., and C. simonsii Baker cultivated in Germany, in which linoleic and palmitic acids were also detected as the major fatty acid components $[9,22,23]$.

The unsaturated fatty acids are known factors associated with the prevention of various chronic and acute diseases, such as cardiovascular diseases, osteoporosis, immune disorders, and cancer [7]. Linoleic acid, the representative of the omega- 6 fatty acid family (essential fatty acids (EFA)), is considered a vital constituent of a healthy human diet, due to its contribution to cholesterol metabolism (regulation of plasma total cholesterol and low-density lipoprotein cholesterol levels and HDL-LDL ratio) and its association with a lower risk of atherosclerosis [24]. Main sources of this compound are plant oils, derived, inter alia, from the seeds of safflower, sunflower, grape, pumpkin, and corn. The available literature data $[25,26]$ indicate that whole fruits of some Rosaceae members, such as Crataegus monogyna Jacq., Prunus spinosa L., and Rubus ulmifolius Schott., might be considered as abundant in linoleic acid, constituting over $10 \%$ of their lipophilic fraction [26]. Our present results indicate that the analyzed Cotoneaster fruits also deserve more attention as rich sources of this compound.

3.2. GC-FID-MS Analysis of Phytosterols and Triterpenoids. Apart from fatty acids, three phytosterols (campesterol, $\beta$-sitosterol, and stigmasterol) and four triterpenes ( $\alpha$ - and $\beta$-amyrins, ursolic and oleanolic acids) were identified in the chloroform extracts of the Cotoneaster fruits, based on GC-FID-MS analysis of their trimethylsilyl ether derivatives (TMSs). As reported in Table 2 and Figure 2, the total content of sterols and triterpenoids, depending on the tested species, was in the range of $154.6-515.6 \mathrm{mg} / 100 \mathrm{~g}$ of fruit (dw) with the highest levels observed for C. splendens $(515.6 \mathrm{mg} / 100 \mathrm{~g} \mathrm{dw})$ and C. nanshan $(438.0 \mathrm{mg} / 100 \mathrm{gdw})$. The dominant compound in all samples was $\beta$-sitosterol, with the levels ranging from 132.2 to $463.3 \mathrm{mg} / 100 \mathrm{gdw}$ (76.5-89.3\% of the total sterols and triterpenes). The highest content of $\beta$-sitosterol was observed for the fruit of C. splendens $(463.3 \mathrm{mg} / 100 \mathrm{~g} \mathrm{dw})$ followed by those of C. nanshan (391.3 mg/100 g dw) and C. horizontalis ( $316.3 \mathrm{mg} / 100 \mathrm{~g} \mathrm{dw}$ ). Other individual components were observed at much lower concentrations, reaching at most $42 \mathrm{mg} / 100 \mathrm{~g} \mathrm{dw}$.

Regarding the phytosterol and triterpenoid profile, the present results are generally similar to the data obtained previously for different organs of Cotoneaster species, although some differences can be noticed in relative proportions of particular compounds. Among the sterols and triterpenoids identified earlier for the $C$. horizontalis branches collected in Egypt, $\alpha$-amyrin was the dominant compound, constituting $14.4 \%$ of the total lipophilic constituents, followed by $\beta$-sitosterol (8.5\%) and stigmasterol (1.1\%) [23]. The ursolic acid was isolated previously from C. simonsii twigs [27], C. racemiflora Desf. twigs [28], and C. microphylla fruits [11], but the present work is the first to describe its quantitative levels in the Cotoneaster plants. 


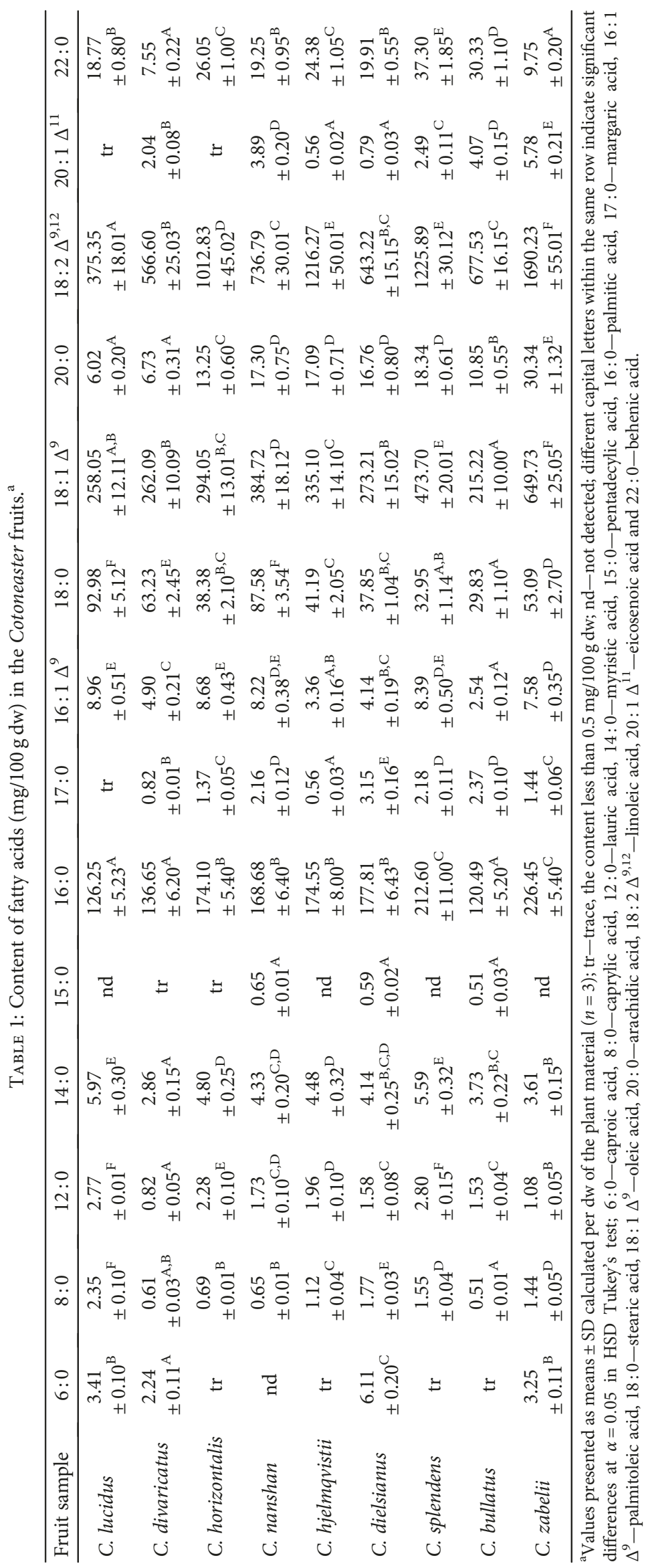




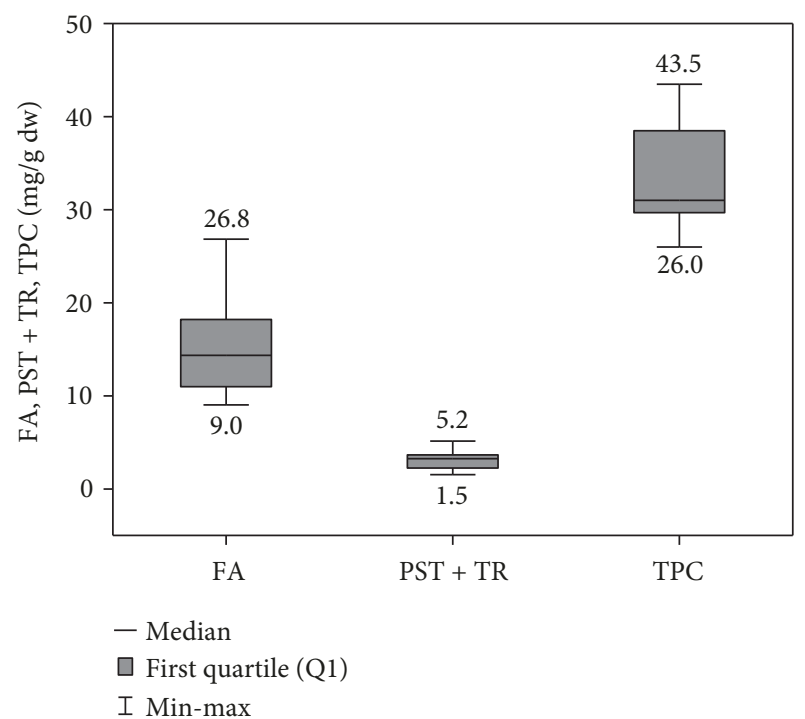

(a)

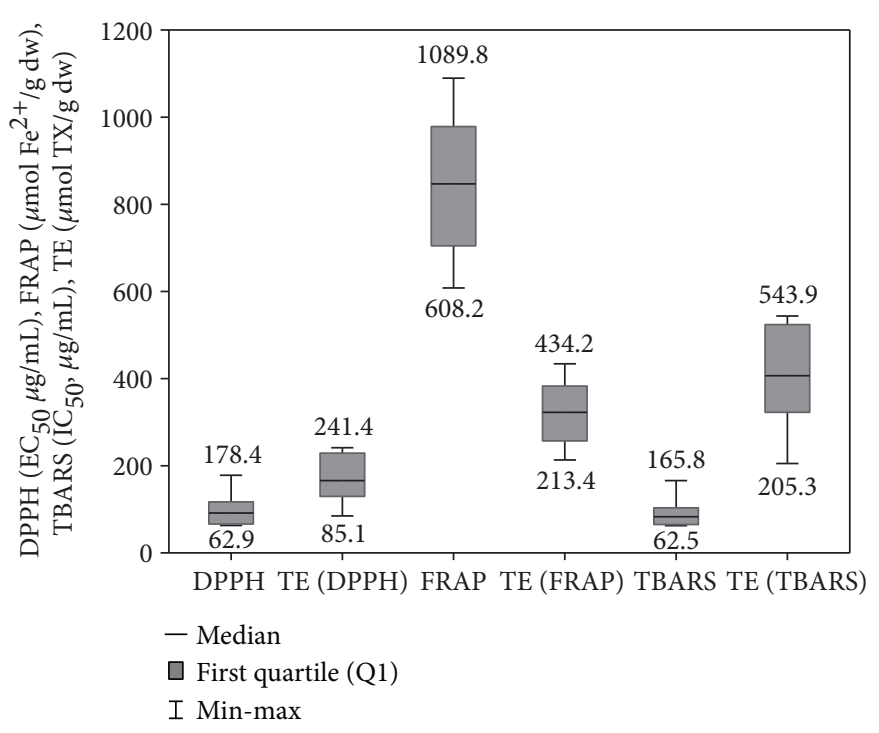

(b)

FIGURE 2: Variability of the measured quantitative and activity parameters among the investigated Cotoneaster fruits. (a) FA, total fatty acids; PS + TR, sum of phytosterols and tritrepenes; TPC, total phenolic content, expressed in gallic acid equivalents (GAE). (b) DPPH, radical scavenging activity expressed as $\mathrm{EC}_{50}$ value; FRAP, ferric reducing antioxidant power; TBARS, inhibition of linoleic acid peroxidation; TE, Trolox ${ }^{\circledR}$ equivalent antioxidant activity.

TABLE 2: Content of phytosterols and triterpenes $(\mathrm{mg} / 100 \mathrm{~g} \mathrm{dw})$ in the Cotoneaster fruits. ${ }^{a}$

\begin{tabular}{lccccccc}
\hline Fruit sample & Campesterol & $\beta$-Sitosterol & Stigmasterol & $\beta$-Amyrin & $\alpha$-Amyrin & Ursolic acid & Oleanolic acid \\
\hline C. lucidus & $6.83 \pm 0.30^{\mathrm{C}}$ & $195.31 \pm 5.31^{\mathrm{B}}$ & $\mathrm{nd}$ & nd & $1.05 \pm 0.05^{\mathrm{A}}$ & $6.61 \pm 0.30^{\mathrm{B}}$ & $15.52 \pm 0.53^{\mathrm{D}}$ \\
C. divaricatus & $9.06 \pm 0.31^{\mathrm{E}}$ & $132.19 \pm 4.23^{\mathrm{A}}$ & $\mathrm{nd}$ & nd & $2.48 \pm 0.07^{\mathrm{B}}$ & $2.21 \pm 0.04^{\mathrm{A}}$ & $8.65 \pm 0.32^{\mathrm{A}, \mathrm{B}}$ \\
C. horizontalis & $6.04 \pm 0.22^{\mathrm{B}, \mathrm{C}}$ & $316.31 \pm 15.03^{\mathrm{D}}$ & $\mathrm{nd}$ & nd & $0.88 \pm 0.02^{\mathrm{A}}$ & $25.45 \pm 1.10^{\mathrm{F}}$ & $17.24 \pm 0.50^{\mathrm{E}}$ \\
C. nanshan & $8.94 \pm 0.40^{\mathrm{E}}$ & $391.26 \pm 17.02^{\mathrm{E}}$ & $\mathrm{nd}$ & nd & $5.26 \pm 0.21^{\mathrm{C}}$ & $6.04 \pm 0.22^{\mathrm{B}}$ & $26.52 \pm 1.05^{\mathrm{F}}$ \\
C. hjelmqvistii & $4.31 \pm 0.12^{\mathrm{A}}$ & $211.99 \pm 10.13^{\mathrm{B}}$ & $\mathrm{nd}$ & $1.17 \pm 0.05^{\mathrm{A}}$ & $14.37 \pm 0.61^{\mathrm{F}}$ & $27.03 \pm 0.98^{\mathrm{F}}$ & $18.41 \pm 0.50^{\mathrm{E}}$ \\
C. dielsianus & $5.38 \pm 0.21^{\mathrm{B}}$ & $181.96 \pm 5.22^{\mathrm{B}}$ & $\operatorname{tr}$ & $2.12 \pm 0.10^{\mathrm{B}}$ & $6.32 \pm 0.24^{\mathrm{D}}$ & $10.49 \pm 0.35^{\mathrm{C}}$ & $7.30 \pm 0.18^{\mathrm{A}}$ \\
C. splendens & $13.11 \pm 0.56^{\mathrm{F}}$ & $463.26 \pm 15.10^{\mathrm{F}}$ & nd & nd & $8.79 \pm 0.30^{\mathrm{E}}$ & $13.42 \pm 0.45^{\mathrm{D}}$ & $17.05 \pm 0.45^{\mathrm{D}, \mathrm{E}}$ \\
C. bullatus & $7.98 \pm 0.31^{\mathrm{D}}$ & $274.47 \pm 12.15^{\mathrm{C}}$ & $2.70 \pm 0.07^{\mathrm{B}}$ & $0.88 \pm 0.04^{\mathrm{A}}$ & $14.15 \pm 0.50^{\mathrm{F}}$ & $41.45 \pm 1.50^{\mathrm{G}}$ & $13.05 \pm 0.52^{\mathrm{C}}$ \\
C. zabelii & $6.77 \pm 0.30^{\mathrm{C}}$ & $273.25 \pm 10.22^{\mathrm{C}}$ & $1.00 \pm 0.01^{\mathrm{A}}$ & nd & $14.89 \pm 0.22^{\mathrm{F}}$ & $20.70 \pm 1.03^{\mathrm{E}}$ & $9.27 \pm 0.36^{\mathrm{B}}$ \\
\hline
\end{tabular}

${ }^{\mathrm{a}}$ Values presented as means $\pm \mathrm{SD}$ calculated per $\mathrm{dw}$ of the plant material $(n=3)$; $\operatorname{tr}-$ trace, the content less than $0.5 \mathrm{mg} / 100 \mathrm{~g}$ dw; nd-not detected; different capital letters within the same row indicate significant differences at $\alpha=0.05$ in HSD Tukey's test.

On the other hand, betulinic acid, reported earlier for C. microphylla fruits [11], was not detected during the present study in any fruit sample.

Phytosterols ( $\beta$-sitosterol, stigmasterol, and their analogues) are important dietary components which help regulate serum lipid profile, reduce total- and LDL-cholesterol levels, and increase HDL/LDL ratio. In addition, plant sterols possess anticancer, anti-inflammatory, and moderate antioxidant activities [29]. For instance, $\beta$-sitosterol, the most abundant plant sterol in the human diet, displays significant effects on reducing the symptoms of benign prostatic hyperplasia and prostate cancer. Moreover, this compound has been associated with antidiabetic, immunomodulatory, and analgesic properties [30]. Phytosterols are found abundantly in nonpolar fractions of plants, and their daily consumption is estimated in the range of $200-400 \mathrm{mg}$ with the main dietary sources being vegetable oils, nuts, cereal products, vegetables, fruits, and berries [30]. They are also known to be present in abundance in the fruits derived from numerous genera of Rosaceae, including Prunus, Crataegus, and Rosa [25]. In the lipid fraction of rosaceous fruits, $\beta$-sitosterol was often identified as the predominant lipophilic compound, constituting usually more than $60 \%$ of the total sterols. As the daily intake of phytosterols $(1.5-2.4 \mathrm{~g})$ required for beneficial health effects, especially for cardiovascular and antiatherogenic protection, is usually higher than consumed with the common diet [30], dietary supplementation is a rational solution, and new plant sources of these biomolecules, such as the Cotoneaster fruits, offer promise in this aspect.

3.3. Polyphenolic Profiling of Fruit Extracts. LC-MS analysis of the hydrophilic (70\% aqueous methanolic) extracts of the Cotoneaster fruits revealed the presence of a number of 


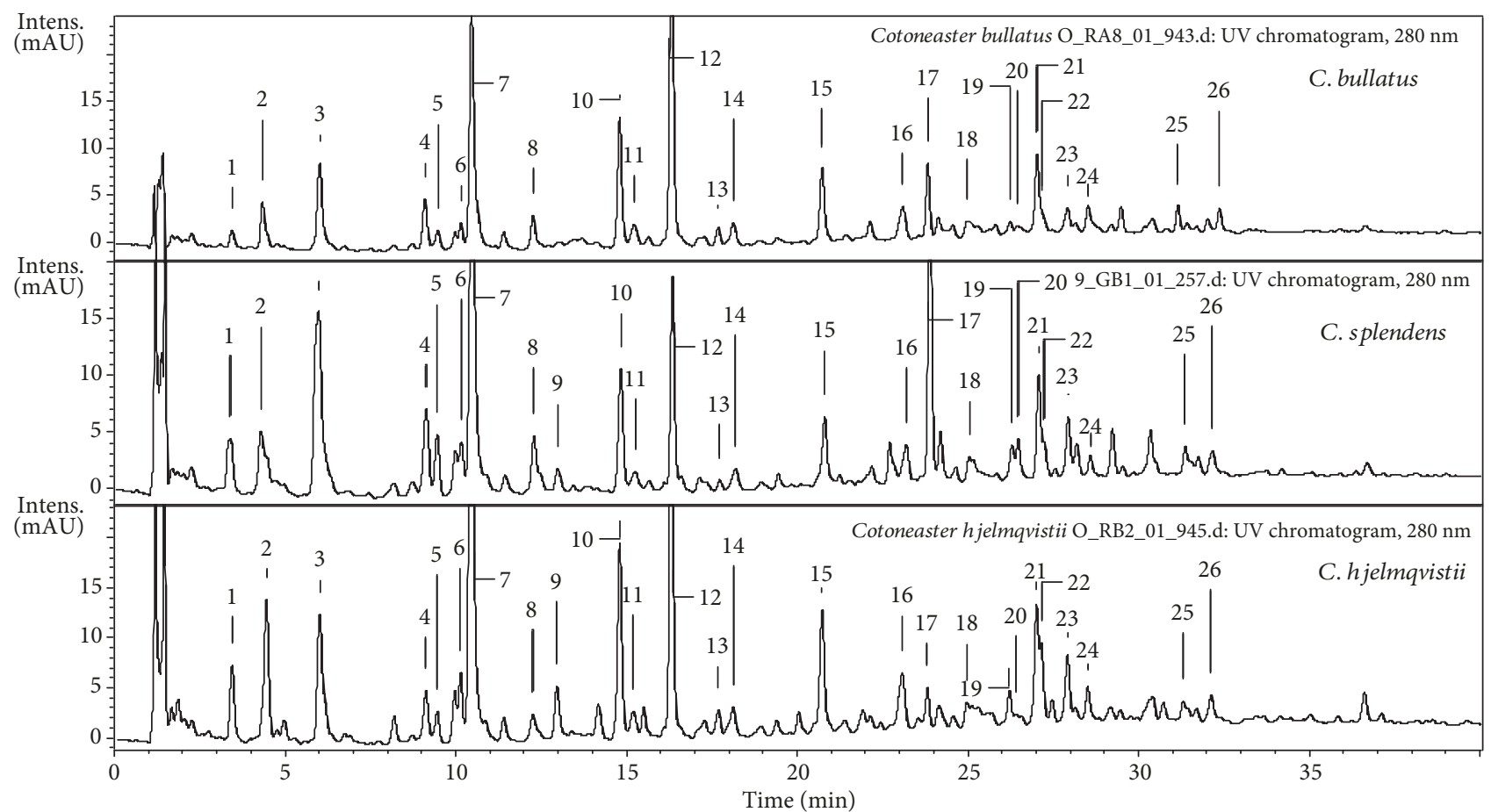

Figure 3: Representative UHPLC-UV chromatograms of the C. bullatus, C. splendens, and C. hjelmqvistii fruit polar extracts $(\lambda=280 \mathrm{~nm})$. The peak numbers refer to those applied in Table 3.

polyphenols (UHPLC peaks 1-26, Figure 3, Table 3) that were fully or tentatively identified by comparison of their chromatographic behavior and ESI-MS ${ }^{3}$ fragmentation pattern with authentic standards or literature values. Three major groups of polyphenols were recognized, including phenolic acids $(3,7$, and 8$)$ and their derivatives $(1,4,5$, and 11), flavan-3-ols including proanthocyanidins $(9,10,12-16,18$, and 24), and flavonoids (17, 20, 21-23, 25, and 26). The recorded UHPLC fingerprints (Table 3 ) indicate that the phenolic profiles of all nine Cotoneaster fruits were qualitatively similar. However, noticeable differences were found in the proportions of individual polyphenols, which allowed the subgroups of species to be distinguished depending on the prevalent phenolic class. A distinctive feature of most Cotoneaster samples, especially $C$. divaricatus, $C$. horizontalis, and $C$. nanshan, was the predominance of phenolic acid derivatives $(1,3-5,7,8$, and 11$)$, mainly caffeoylquinic acids, with the dominant peak being chlorogenic acid (7). On the other hand, C. zabelii, C. bullatus, and C. hjelmqvistii contained relatively high amounts of flavan-3-ols and proanthocyanidins $(9,10,12-16,18$, and 24$)$, with dominating (-)-epicatechin (12). The contribution of flavonoids $(17,20,21-23,25$, and 26) to the overall phenolic fraction was generally the lowest, but C. splendens was distinguished by a particularly large proportion of quercetin 3-(2" -xylosyl)-galactoside (17), and C. dielsianus contained a relatively higher level of hyperoside (21).

This report is the first comprehensive study of the LC-MS characteristics of the Cotoneaster fruits; the previous studies on C. integerrimus and C. pannosus have focused only on a selected aspect (HPLC-PDA) of their polyphenolic profiles $[9,12]$. In contrast to the present results, the occurrence of low-molecular phenolic acids, including shikimic, $p$-coumaric, and benzoic acids, has been previously reported, and this phenomenon may be explained by the individual attributes of the tested samples or by differences in the methodology employed for the structural identification. On the other hand, the reported high level of (-)-epicatechin in the fruits of $C$. integerrimus [12] indicates its similarity to those of $C$. zabelii and C. bullatus analyzed in the present study.

The total phenolic content (TPC) of the $70 \%$ aqueous methanolic extracts of the Cotoneaster fruits was determined by the Folin-Ciocalteu photometric assay, commonly used to estimate phenolic metabolites as gallic acid equivalents (GAE). As shown in Table 4 and Figure 2, the TPC values in the analyzed fruits varied from 26.0 to $43.5 \mathrm{mg} \mathrm{GAE} / \mathrm{g}$ of fruit dw. The highest phenolic content was found for the fruits of C. hjelmqvistii and C. zabelii ( 43.5 and $43.0 \mathrm{mg} / \mathrm{g} \mathrm{dw}$, respectively), followed by those of $C$. splendens and C. bullatus ( 38.5 and $37.3 \mathrm{mg} / \mathrm{g} \mathrm{dw}$, respectively). The level of phenolics in these species is comparable with those observed for other Rosaceae fruits reported in the literature as rich sources of natural polyphenols, for example, Aronia melanocarpa (Michx.) Elliott (34.4-78.5 mg GAE/gdw; [3]) and Sorbus species (22.4-29.8 mg GAE/g dw; [16]).

The presence of polyphenolic compounds in fruits and vegetables is strongly linked with the beneficial effects of these food products for human health, and the influence of polyphenols on closely intertwined processes of inflammation and oxidative stress is recognized as the most feasible mode of this action. As free radical scavengers, metal chelators, prooxidant and proinflammatory enzyme inhibitors, and modifiers of cell signaling pathways, polyphenols are 


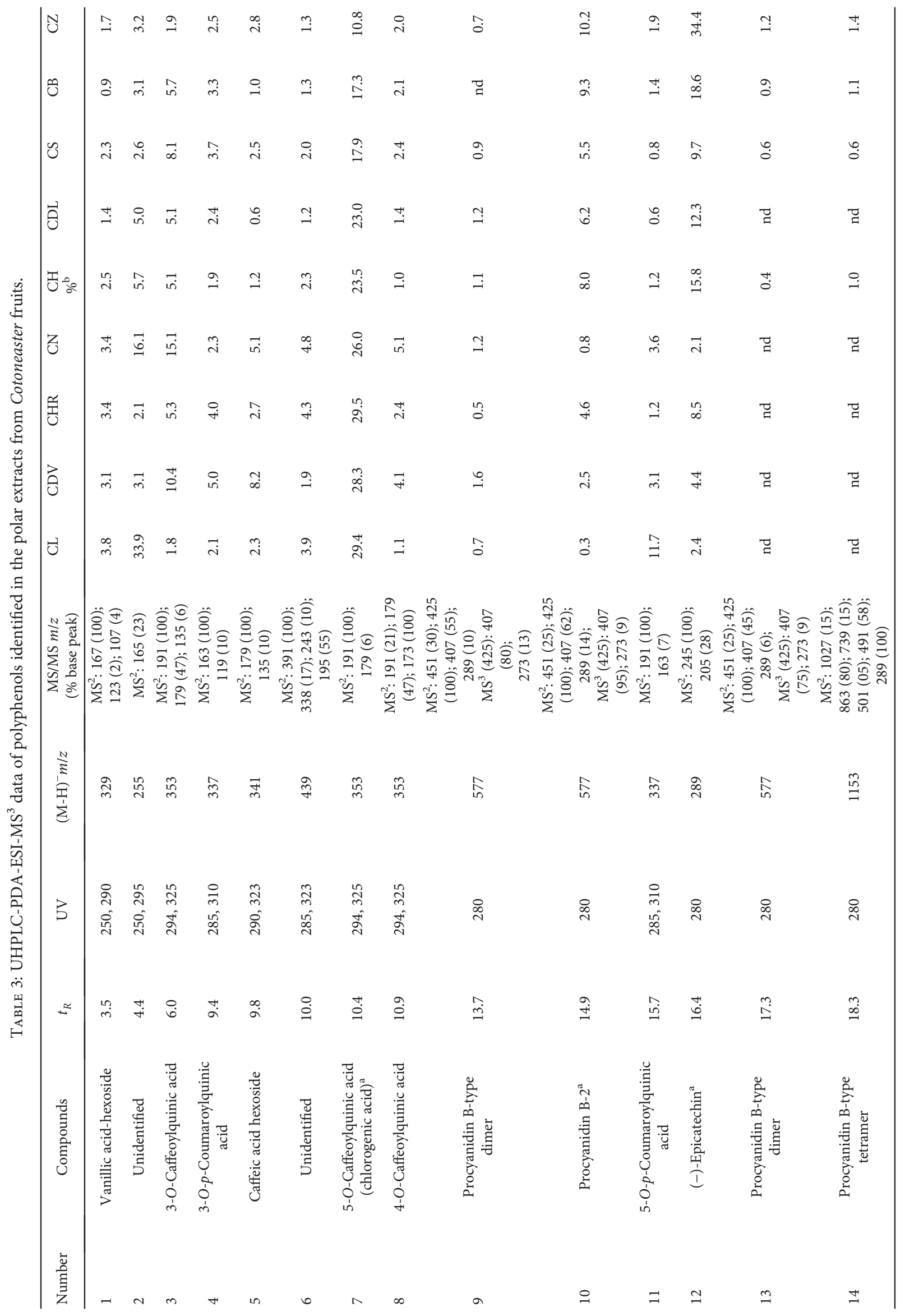




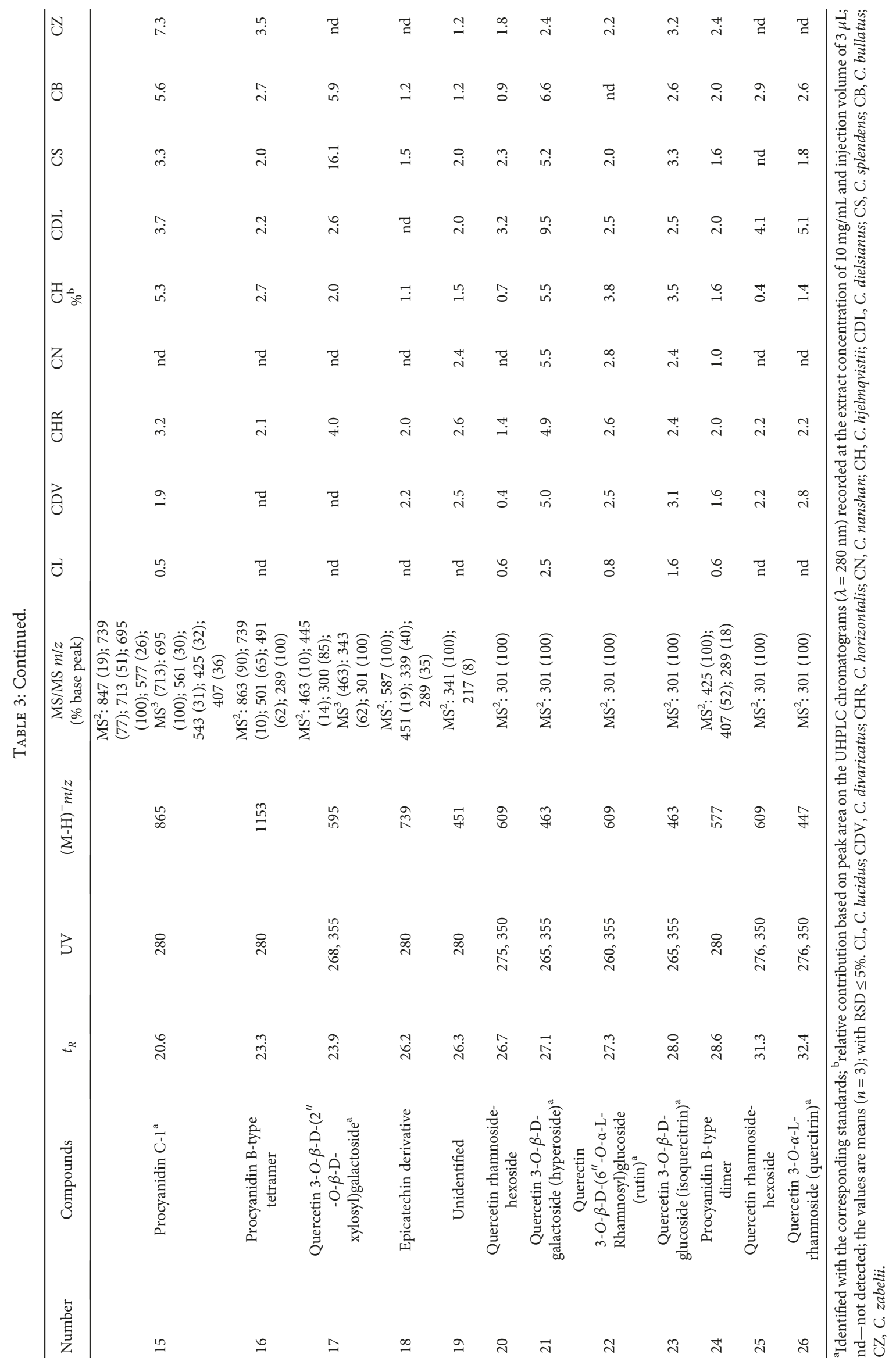


TABLE 4: Total phenolic content (TPC) and antioxidant activity (DPPH, FRAP, and TBARS tests) of the Cotoneaster fruits and standard antioxidants.

\begin{tabular}{|c|c|c|c|c|c|c|c|}
\hline \multirow{2}{*}{$\begin{array}{l}\text { Fruit sample/ } \\
\text { standard }\end{array}$} & \multirow{2}{*}{$\begin{array}{c}\mathrm{TPC}^{\mathrm{a}} \\
(\mathrm{mg} \mathrm{GAE} / \mathrm{g})\end{array}$} & \multicolumn{2}{|c|}{$\begin{array}{l}\text { Radical scavenging activity } \\
\text { DPPH }^{\mathrm{b}}\end{array}$} & \multicolumn{2}{|c|}{ Reducing power ${ }^{c}$} & \multicolumn{2}{|c|}{ LA-peroxidation TBARS ${ }^{\mathrm{d}}$} \\
\hline & & $\begin{array}{c}\mathrm{EC}_{50} \\
(\mu \mathrm{g} / \mathrm{mL})\end{array}$ & $\begin{array}{c}\mathrm{TE} \\
(\mu \mathrm{mol} \mathrm{TE} / \mathrm{g})\end{array}$ & $\begin{array}{c}\text { FRAP } \\
\left(\mathrm{mmol} \mathrm{Fe}^{2+} / \mathrm{g}\right)\end{array}$ & $\begin{array}{c}\mathrm{TE} \\
(\mu \mathrm{mol} \mathrm{TE} / \mathrm{g})\end{array}$ & $\begin{array}{c}\mathrm{IC}_{50} \\
(\mu \mathrm{g} / \mathrm{mL})\end{array}$ & $\begin{array}{c}\mathrm{TE} \\
(\mu \mathrm{mol} \mathrm{TE} / \mathrm{g})\end{array}$ \\
\hline C. lucidus & $28.70 \pm 1.01^{\mathrm{B}}$ & $123.41 \pm 1.70^{\mathrm{E}}$ & $122.75 \pm 1.69^{\mathrm{C}}$ & $0.70 \pm 0.01^{\mathrm{B}}$ & $257.22 \pm 4.96^{\mathrm{B}, \mathrm{C}}$ & $108.70 \pm 4.11^{\mathrm{F}}$ & $314.84 \pm 6.03^{\mathrm{C}}$ \\
\hline C. divaricatus & $29.71 \pm 0.91^{\mathrm{B}}$ & $91.47 \pm 2.01^{\mathrm{C}}$ & $165.58 \pm 3.62^{\mathrm{D}}$ & $0.76 \pm 0.01^{\mathrm{C}}$ & $281.61 \pm 4.43^{\mathrm{C}}$ & $83.16 \pm 0.58^{\mathrm{D}}$ & $406.94 \pm 1.43^{\mathrm{D}}$ \\
\hline C. horizontalis & $30.50 \pm 0.72^{\mathrm{B}}$ & $93.32 \pm 1.90^{\mathrm{C}}$ & $162.38 \pm 3.31^{\mathrm{D}}$ & $0.85 \pm 0.01^{\mathrm{D}}$ & $322.75 \pm 4.06^{\mathrm{D}}$ & $84.89 \pm 2.11^{\mathrm{D}}$ & $401.23 \pm 5.03^{\mathrm{D}}$ \\
\hline C. nanshan & $26.02 \pm 0.74^{\mathrm{A}}$ & $178.35 \pm 2.81^{\mathrm{F}}$ & $84.91 \pm 1.33^{\mathrm{B}}$ & $0.61 \pm 0.01^{\mathrm{A}}$ & $213.41 \pm 4.42^{\mathrm{A}}$ & $165.76 \pm 3.74^{\mathrm{G}}$ & $205.30 \pm 2.33^{\mathrm{B}}$ \\
\hline C. hjelmqvistii & $43.50 \pm 1.21^{\mathrm{D}}$ & $64.51 \pm 0.84^{\mathrm{B}}$ & $234.84 \pm 2.91^{\mathrm{E}, \mathrm{F}}$ & $1.05 \pm 0.02^{\mathrm{F}}$ & $414.38 \pm 11.14^{\mathrm{F}, \mathrm{G}}$ & $62.96 \pm 1.10^{\mathrm{C}}$ & $532.92 \pm 4.63^{\mathrm{E}, \mathrm{F}}$ \\
\hline C. dielsianus & $31.02 \pm 1.02^{\mathrm{B}}$ & $117.10 \pm 2.40^{\mathrm{D}}$ & $129.37 \pm 2.65^{\mathrm{C}}$ & $0.67 \pm 0.03^{\mathrm{B}}$ & $240.90 \pm 13.83^{\mathrm{A}, \mathrm{B}}$ & $103.72 \pm 2.58^{\mathrm{E}}$ & $322.66 \pm 3.98^{\mathrm{C}}$ \\
\hline C. splendens & $38.51 \pm 0.81^{\mathrm{C}}$ & $67.15 \pm 1.80^{\mathrm{B}}$ & $225.49 \pm 6.04^{\mathrm{E}}$ & $0.98 \pm 0.01^{\mathrm{E}}$ & $383.06 \pm 6.24^{\mathrm{E}, \mathrm{F}}$ & $66.21 \pm 2.94^{\mathrm{C}}$ & $518.18 \pm 11.79^{\mathrm{E}}$ \\
\hline C. bullatus & $37.31 \pm 0.80^{\mathrm{C}}$ & $66.31 \pm 1.70^{\mathrm{B}}$ & $228.54 \pm 5.86^{\mathrm{E}}$ & $0.97 \pm 0.01^{\mathrm{E}}$ & $378.87 \pm 2.90^{\mathrm{E}}$ & $64.99 \pm 1.55^{\mathrm{C}}$ & $523.90 \pm 6.30^{\mathrm{E}, \mathrm{F}}$ \\
\hline C. zabelii & $43.02 \pm 1.11^{\mathrm{D}}$ & $62.93 \pm 1.91^{\mathrm{B}}$ & $240.93 \pm 7.28^{\mathrm{F}}$ & $1.09 \pm 0.04^{\mathrm{G}}$ & $434.27 \pm 20.50^{\mathrm{G}}$ & $62.54 \pm 1.32^{\mathrm{C}}$ & $543.86 \pm 5.76^{\mathrm{F}}$ \\
\hline QU & - & $1.70 \pm 0.11^{\mathrm{A}}$ & $8.96 \pm 0.58^{\mathrm{A}}$ & $31.20 \pm 0.98^{\mathrm{K}}$ & $11878.15 \pm 15.20^{\mathrm{J}}$ & $1.85 \pm 0.12^{\mathrm{A}}$ & $18.37 \pm 1.69^{\mathrm{A}}$ \\
\hline BHA & - & $2.90 \pm 0.15^{\mathrm{A}}$ & $5.24 \pm 0.27^{\mathrm{A}}$ & $16.14 \pm 0.77^{\mathrm{I}}$ & $7726.31 \pm 10.52^{\mathrm{H}}$ & $3.16 \pm 0.22^{\mathrm{A}}$ & $10.76 \pm 1.06^{\mathrm{A}}$ \\
\hline $\mathrm{BHT}$ & - & $6.50 \pm 0.13^{\mathrm{A}}$ & $2.34 \pm 0.05^{\mathrm{A}}$ & $18.89 \pm 0.45^{\mathrm{J}}$ & $9247.66 \pm 12.30^{\mathrm{I}}$ & $9.31 \pm 0.16^{\mathrm{B}}$ & $3.64 \pm 0.09^{\mathrm{A}}$ \\
\hline $\mathrm{TX}$ & - & $3.80 \pm 0.20^{\mathrm{A}}$ & - & $9.34 \pm 0.35^{\mathrm{H}}$ & - & $8.47 \pm 0.45^{\mathrm{B}}$ & - \\
\hline
\end{tabular}

${ }^{a-d}$ Results expressed as means \pm SD calculated per dw of the plant material $(n=3)$; different capital letters within the same row indicate significant differences at $\alpha=0.05$ in HSD Tukey's test. ${ }^{\mathrm{a} T}$ Total phenolic content (TPC), expressed in gallic acid equivalents (GAE). ${ }^{\mathrm{b}}$ Scavenging efficiency in the DPPH test, the amount of the plant materials or standards required for $50 \%$ reduction of the initial DPPH concentration expressed as $\mathrm{EC}_{50}$, effective concentration. ${ }^{c} \mathrm{Ferric}$ reducing antioxidant power. ${ }^{\mathrm{d}}$ Ability to inhibit linoleic acid (LA) peroxidation monitored by TBARS test and expressed as $\mathrm{IC}_{50}$, concentration of plant materials or standards needed to decrease the LA-peroxidation by $50 \%$; TE, Trolox ${ }^{\circledR}$ equivalent antioxidant activity. Standards: QU, quercetin; BHA, butylated hydroxyanisole; BHT, 2,6-di-tert-butyl-4-methylphenol; TX, Trolox ${ }^{\circledR}$.

effective agents preventing damages related to the oxidative stress and inflammation implicated in the etiology and progression of numerous chronic diseases, including cardiovascular diseases, diabetes mellitus, neurodegenerative disorders, and cancer [31-33]. The occurrence of polyphenolic compounds in the investigated fruits might thus largely define their bioactivity, especially that Cotoneaster-derived polyphenols have been previously linked with strong antioxidant capacity in our earlier study regarding the leaves [34].

3.4. Biological Activity. The above presented phytochemical studies proved that fruits of Cotoneaster species are indeed a rich source of diverse phytochemicals with a wide spectrum of recognized biological properties. However, based on the results of the quantitative studies, the polyphenolic fraction with the highest content would appear to have the greatest beneficial health effects of the fruits in a human organism. Thus, further studies were focused on providing a more detailed insight into potential mechanisms of the activity of the hydrophilic components, that is, their antiinflammatory and antioxidant effects.

3.4.1. Inhibitory Effects on Two Enzymes Involved in Inflammation. Inflammation is a complex process that constitutes a part of the immune system defense against harmful stimuli, but may lead to negative effects if uncontrolled. The inflammatory response is regulated by numerous enzymes and mediators and thus can be intercepted at different points, and several of these key enzymes, including lipoxygenases (LOX) and hyaluronidases (HYAL), are most often used to determine the anti-inflammatory potential of natural products [35]. LOX catalyze the diooxygenation of arachidonic acid to form hydroperoxides, the first step in the biosynthesis of several proinflammatory mediators [36]. HYAL, on the other hand, are highly specific hydrolases that degrade hyaluronic acid, an important component of the extracellular matrix, thus increasing the permeability of the tissues and facilitating the spread of inflammation [37]. Our present findings indicate that all fruit extracts inhibit the activity of LOX and HYAL in a dosedependent manner (Table 5). The strongest inhibitory effect towards LOX was demonstrated by the leaf extracts of C. hjelmqvistii and C. zabelii $\left(\mathrm{IC}_{50}=7.70\right.$ and $9.97 \mu \mathrm{g} / \mathrm{U}$, respectively), while the activity of HYAL was most strongly hindered by the leaf extract of $C$. lucidus $\left(\mathrm{IC}_{50}=16.44 \mu \mathrm{g} / \mathrm{U}\right)$. The activity of the extracts was weaker in comparison to indomethacin $\left(\mathrm{IC}_{50}=1.89 \mu \mathrm{g} / \mathrm{U}\right.$ for $\mathrm{LOX}$ and $5.60 \mu \mathrm{g} / \mathrm{U}$ for HYAL), but after recalculating the results to adjust for the actual polyphenol content (which gives $\mathrm{IC}_{50}$ values in the range of $0.33-0.77 \mu \mathrm{g} / \mathrm{U}$ for LOX and $0.47-1.93 \mu \mathrm{g} /$ $\mathrm{U}$ for HYAL inhibition), the activity of the extracts looks quite advantageous in comparison to the positive standard. The anti-inflammatory potential of Cotoneaster polyphenols is further confirmed by the high activity of (-)-epicatechin, quercetin, and chlorogenic acid, the main constituents of the investigated leaf extracts.

3.4.2. Antioxidant Activity in Chemical Models. The basic antioxidant mechanism of Cotoneaster polyphenols was verified in chemical models using three complementary in vitro assays: DPPH and FRAP tests, two of the most frequently 
TABLE 5: Inhibitory effects of Cotoneaster fruit extracts and standards towards lipoxygenase (LOX) and hyaluronidase (HYAL).

\begin{tabular}{|c|c|c|c|c|}
\hline \multirow[b]{2}{*}{ Fruit sample/standard } & \multicolumn{2}{|c|}{ LOX } & \multicolumn{2}{|c|}{ HYAL } \\
\hline & $\begin{array}{c}\mathrm{IC}_{50}{ }^{\mathrm{a}} \\
(\mu \mathrm{g} / \mathrm{mL})\end{array}$ & $\begin{array}{l}\mathrm{IC}_{50}^{\mathrm{b}} \\
(\mu \mathrm{g} / \mathrm{U})\end{array}$ & $\begin{array}{c}\mathrm{IC}_{50}{ }^{\mathrm{a}} \\
(\mu \mathrm{g} / \mathrm{mL})\end{array}$ & $\begin{array}{l}\mathrm{IC}_{50}{ }^{\mathrm{b}} \\
(\mu \mathrm{g} / \mathrm{U})\end{array}$ \\
\hline C. lucidus & $487.75 \pm 6.57^{\mathrm{F}}$ & $13.29 \pm 0.18^{\mathrm{F}}$ & $25.65 \pm 0.95^{\mathrm{C}}$ & $16.44 \pm 0.61^{\mathrm{C}}$ \\
\hline C. divaricatus & $479.98 \pm 12.79^{\mathrm{F}}$ & $13.08 \pm 0.35^{\mathrm{F}}$ & $34.22 \pm 1.48^{\mathrm{D}}$ & $21.93 \pm 0.95^{\mathrm{D}}$ \\
\hline C. horizontalis & $421.85 \pm 5.78^{\mathrm{E}}$ & $11.50 \pm 0.16^{\mathrm{E}}$ & $40.51 \pm 2.11^{\mathrm{E}, \mathrm{F}, \mathrm{G}}$ & $25.97 \pm 1.35^{\mathrm{E}, \mathrm{F}, \mathrm{G}}$ \\
\hline C. nanshan & $626.16 \pm 5.04^{\mathrm{H}}$ & $17.07 \pm 0.14^{\mathrm{H}}$ & $45.64 \pm 0.76^{\mathrm{G}}$ & $29.25 \pm 0.49^{\mathrm{G}}$ \\
\hline C. hjelmqvistii & $290 \pm 2.75^{\mathrm{C}}$ & $7.70 \pm 0.07^{\mathrm{C}}$ & $44.44 \pm 1.72^{\mathrm{F}, \mathrm{G}}$ & $28.48 \pm 1.10^{\mathrm{F}, \mathrm{G}}$ \\
\hline C. dielsianus & $914.97 \pm 2.15^{J}$ & $24.94 \pm 0.06^{J}$ & $35.07 \pm 2.60^{\mathrm{D}, \mathrm{E}}$ & $22.48 \pm 1.66^{\mathrm{D}, \mathrm{E}}$ \\
\hline C. splendens & $734.25 \pm 5.86^{\mathrm{I}}$ & $20.01 \pm 0.16^{\mathrm{I}}$ & $34.36 \pm 0.11^{\mathrm{D}}$ & $22.03 \pm 0.07^{\mathrm{D}}$ \\
\hline C. bullatus & $585.43 \pm 16.14^{\mathrm{G}}$ & $15.96 \pm 0.44^{\mathrm{G}}$ & $39.04 \pm 0.82^{\mathrm{D}, \mathrm{E}, \mathrm{F}}$ & $25.03 \pm 0.53^{\mathrm{D}, \mathrm{E}, \mathrm{F}}$ \\
\hline C. zabelii & $375.87 \pm 9.89^{\mathrm{D}}$ & $9.97 \pm 0.26^{\mathrm{D}}$ & $33.33 \pm 2.12^{\mathrm{D}}$ & $21.37 \pm 1.36^{\mathrm{D}}$ \\
\hline QU & $69.60 \pm 2.62^{\mathrm{A}}$ & $2.46 \pm 0.01^{\mathrm{A}}$ & $21.04 \pm 1.03^{\mathrm{C}}$ & $13.87 \pm 0.06^{\mathrm{C}}$ \\
\hline ECA & $124.38 \pm 1.56^{\mathrm{B}}$ & $3.39 \pm 0.04^{\mathrm{B}}$ & $18.51 \pm 0.50^{\mathrm{B}}$ & $11.87 \pm 0.32^{\mathrm{B}}$ \\
\hline $\mathrm{CHA}$ & $151.71 \pm 7.52^{\mathrm{B}}$ & $4.14 \pm 0.21^{\mathrm{B}}$ & $20.35 \pm 0.36^{\mathrm{B}}$ & $13.05 \pm 0.23^{\mathrm{B}}$ \\
\hline IND & $90.12 \pm 0.40^{\mathrm{A}}$ & $1.89 \pm 0.10^{\mathrm{A}}$ & $8.61 \pm 0.22^{\mathrm{A}}$ & $5.60 \pm 0.07^{\mathrm{A}}$ \\
\hline
\end{tabular}

Results expressed as means \pm SD calculated per dry weight $(\mathrm{dw})$ of the extracts; different capital letters within the same row indicate significant differences at $\alpha=0.05$ in HSD Tukey's test. Standards: QU, quercetin; ECA, (-)-epicatechin; CHA, chlorogenic acid; IND, indomethacin. Ability to inhibit lipoxygenase (LOX) and hyaluronidase (HYAL) calculated as the amount of analyte needed for $50 \%$ inhibition of enzyme activity was expressed as follows: ${ }^{\mathrm{a}} \mu \mathrm{g}$ of the dry extracts or standards/mL of the enzyme solution and ${ }^{\mathrm{b}} \mu \mathrm{g}$ of the extracts/enzyme units $(\mathrm{U})$.

employed SET (single electron transfer) type methods, and the inhibition of AAPH-induced linoleic acid peroxidation test (monitored by TBARS assay), a more physiologically relevant system which involves the HAT (hydrogen atom transfer) mechanism. In all of the applied tests, the investigated fruits displayed concentration-dependent activity with the capacity parameters (expressed in $\mu \mathrm{mol} \mathrm{TE} / \mathrm{g} \mathrm{dw}$ ) of a similar order of magnitude, which shows that Cotoneaster antioxidants can effectively act via both basic mechanisms. The highest activity in comparison to the natural (quercetin) and synthetic standards (BHA and BHT) were observed in the FRAP and TBARS assays for all fruits (Table 4 and Figure 2). In all tests, the fruits of C. zabelii, C. hjelmqvistii, C. bullatus, and C. splendens, indicated in the present study as the richest sources of polyphenols, displayed the highest antioxidant efficiency, with the activity parameters varying in the narrow range of $225.5-240.9 \mu \mathrm{mol} \mathrm{TE} / \mathrm{g} \mathrm{dw}$ (DPPH), 378.9-434.3 $\mu \mathrm{mol}$ TE/g (FRAP), and 518.2$543.9 \mu \mathrm{mol} \mathrm{TE} / \mathrm{g}$ (TBARS), respectively. Interestingly, these were the species that also exhibited the relatively largest proportions of proanthocyanidins/flavan-3-ols (C. zabelii, C. bullatus, C. splendens) or quercetin 3-(2"-xylosyl)-glucoside (C. hjelmqvistii), which suggest that these polyphenols play a significant role in the activity of fruits. Additionally, the close connection between the phenolic levels and antioxidant parameters was also evidenced by statistically significant linear correlations between TPCs and the results of the DPPH $(|r|=0.9352, p<0.001)$, FRAP $(|r|=0.9491$, $p<0.001)$, and TBARS $(|r|=0.9116, p<0.001)$ tests.

3.4.3. Protective Effects on Human Plasma Components Exposed to Oxidative Stress. To provide a more detailed insight into the antioxidant effects of Cotoneaster polyphenols, the four most promising species (C. zabelii, C. bullatus,
C. splendens, and C. hjelmqvistii) were selected for further studies in a biological model. Since according to traditional application and our present results, Cotoneaster fruits appear to be promising sources of phytochemicals with properties especially advantageous for the circulatory system (i.e., linoleic acid and $\beta$-sitosterol), a human plasma model was selected to evaluate their additional benefits for cardiovascular health, this time mediated by polyphenols. This approach allowed for the in vitro monitoring of the protective effects of the extracts towards human plasma components under oxidative stress conditions. The peroxynitrite $\left(\mathrm{ONOO}^{-}\right)$used for inducing oxidative stress is a known in vivo-operating oxidant, responsible for structural changes in plasma proteins and lipids and implicated in numerous oxidative stress-related disorders [38]. The concentrations of $\mathrm{ONOO}^{-}$ $(100$ and $150 \mu \mathrm{M})$ selected for the study enabled quantitative measurements of the resulting modifications in plasma components, but may be also regarded as physiologically-relevant as they can be reached in vivo in local compartments, for example, during a serious inflammation of blood vessels [39].

The addition of $\mathrm{ONOO}^{-}$to the plasma samples resulted in an overall decrease $(p<0.001)$ in the nonenzymatic antioxidant capacity of the plasma, measured as the FRAP parameter, and in oxidative and nitrative alterations of its protein and lipid components, which was evidenced by a significant increase $(p<0.001)$ in lipid peroxidation biomarkers (lipid hydroperoxides and TBARS), a noticeable rise $(p<0.001)$ in 3-nitrotyrosine level (marker of protein nitration), and a decrease $(p<0.001)$ in the level of thiol groups (marker of protein oxidation). On the other hand, in the plasma samples incubated with $\mathrm{ONOO}^{-}$in the presence of Cotoneaster extracts $(1-50 \mu \mathrm{g} / \mathrm{mL})$, the extent of oxidative/ nitrative damage to both proteins and lipids was noticeably limited $(p<0.05)$, regardless of the tested species and the 


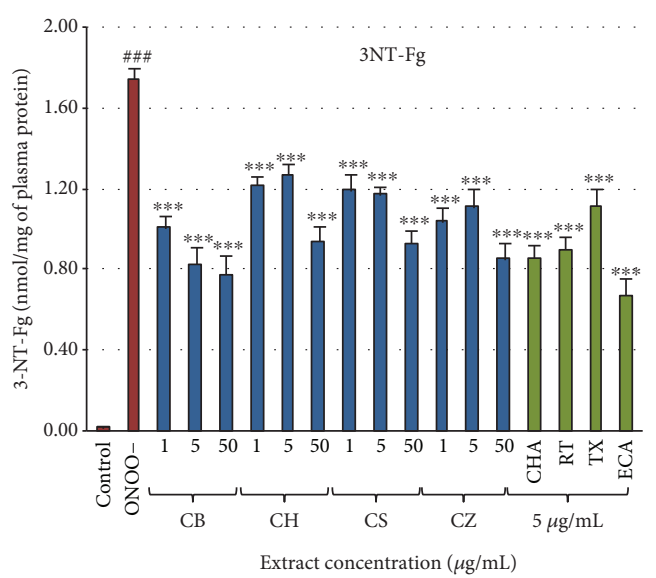

(a)

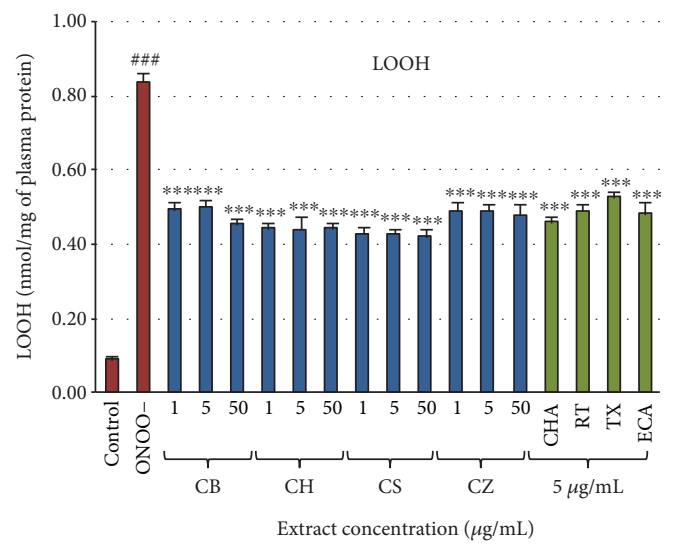

(c)

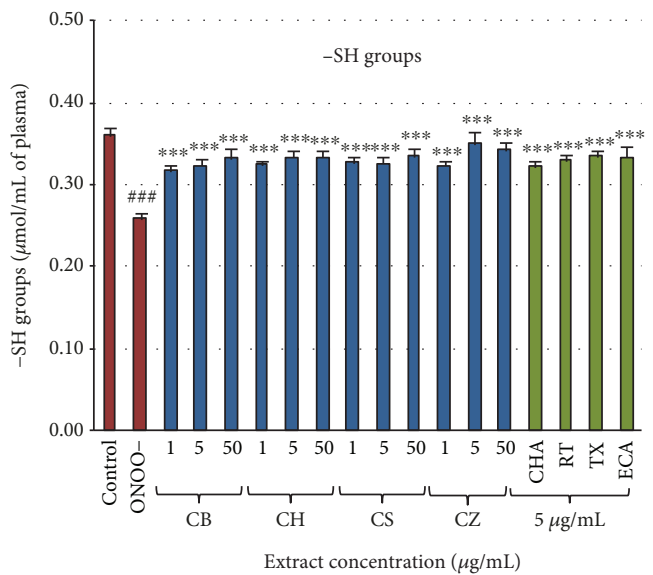

(b)

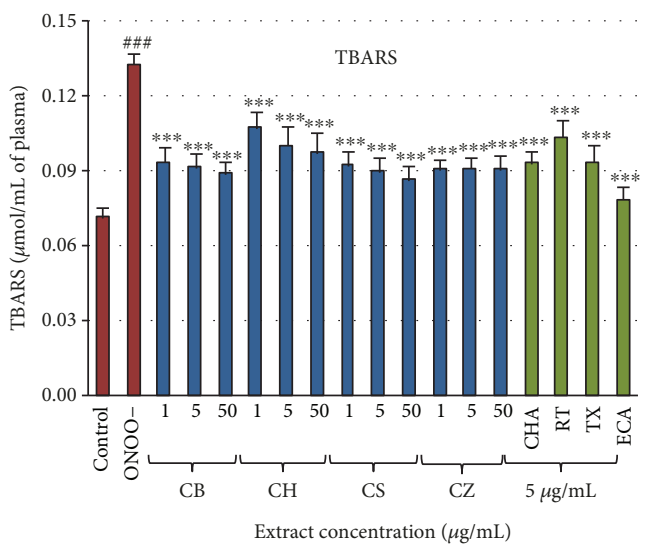

(d)

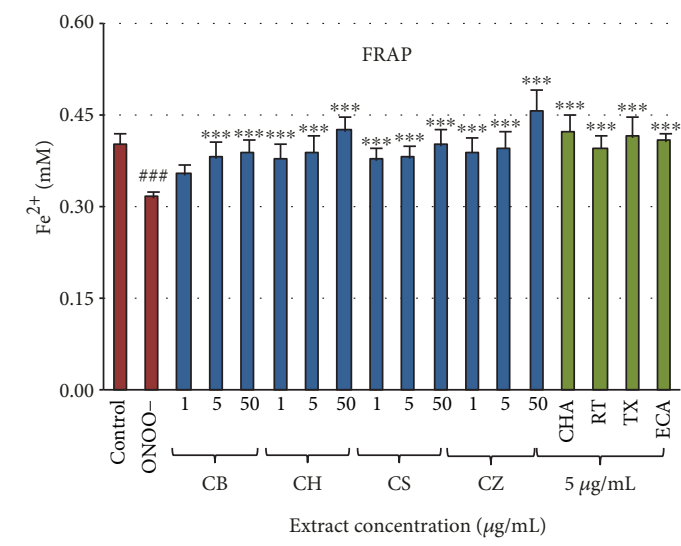

(e)

FIGURE 4: Effects of the Cotoneaster fruit extracts on human plasma exposed to oxidative stress: (a) effects on the nitration of tyrosine residues in plasma proteins and formation of 3-nitrotyrosine (3-NT-Fg); (b) effects on the oxidation of free thiol groups (-SH); effects on the peroxidation of plasma lipids including (c) formation of lipid hydroperoxides (LOOH), and (d) thiobarbituric acid-reactive substances (TBARS); (e) effects on ferric reducing ability of blood plasma (FRAP). Results expressed as means $\pm \mathrm{SE}(n=8)$ for repeated measures: ${ }^{\# \#} p<0.001$, for $\mathrm{ONOO}^{-}$-treated plasma (without the extracts) versus control plasma, and ${ }^{* * *} p<0.001$ for plasma treated with $\mathrm{ONOO}^{-}$in the presence of the investigated extracts (1-50 $\mu \mathrm{g} / \mathrm{mL})$ or the standards $(5 \mu \mathrm{g} / \mathrm{mL})$. CB, C. bullatus; CH, C. hjelmqvistii; CS, C. splendens; CZ, C. zabelii. Standards: CHA, chlorogenic acid; RT, rutin; TX, Trolox ${ }^{\circledR}$; ECA, (-)-epicatechin.

extract concentration. As shown in Figures 4(a) and 4(b), even at the lowest concentrations of $1 \mu \mathrm{g} / \mathrm{mL}$, the extracts were able to reduce tyrosine nitration by about $29-42 \%$ and thiol group oxidation by about $24-26 \%$, while at the concentration of $50 \mu \mathrm{g} / \mathrm{mL}$ the effectiveness rose to $46-55 \%$ and 29-32\%, respectively. Moreover, as demonstrated in Figures 4(c) and 4(d), all fruit samples inhibited the generation of plasma lipid hydroperoxides by $40-50 \%$ and reduced 
TBARS levels by $19-35 \%$. All extract-treated samples, apart from those fortified with $1 \mu \mathrm{g} / \mathrm{mL}$ of $C$. bullatus extract, demonstrated a statistically significant $(p<0.001)$ improvement in the nonenzymatic antioxidant capacity of blood plasma of up to $44 \%$ in comparison to the samples not protected by the extracts (Figure $4(\mathrm{e})$ ). In most cases, little difference was observed in the activity between the tested fruits; however, the inhibition of tyrosine nitration assay found C. bullatus and C. zabelii displaying stronger activity than the other two extracts at all concentrations tested $(p<0.05)$. A dose dependency was noticeable for $C$. bullatus and $C$. splendens in antinitrative activity (Figure 4(a)) and for most Cotoneaster species in the TBARS test, with the exception of C. zabelii (Figure 4(d)). Some significant correlations were also found, between the TPCs and the activity parameters. The most prominent was the relationship for the FRAP assay $(|r|=0.7587, p<0.01)$. In the tests for protein protection, the correlation between the percentage inhibition of tyrosine nitration and phenolic level was stronger $(|r|=0.6774$, $p<0.05)$ than the analogous relationship for the reduction of thiol group oxidation $(|r|=0.4885, p<0.05)$. Contrastingly, the correlations in the lipid peroxidation assays were not statistically significant $(p>0.05)$.

The effectiveness of the extracts was further supported by the fact that in all of the tests, the observed antioxidant effects of the fruit extracts at the corresponding concentration levels $(5 \mu \mathrm{g} / \mathrm{mL})$ were similar or higher to that of Trolox ${ }^{\circledR}$, a synthetic analog of vitamin $\mathrm{E}$ often used as a positive standard in antioxidant studies. Moreover, the significant activity of rutin, chlorogenic acid, and, especially, (-)-epicatechin confirm the important role of polyphenols in the capacity of the extracts.

The wide range of the extract concentrations tested $(1-50 \mu \mathrm{g} / \mathrm{mL})$ was in accordance with the general practice of in vitro studies [20] and allowed for the study of different interactions in the system. Additionally, the lower levels $(1-5 \mu \mathrm{g} / \mathrm{mL})$ might be considered physiologically-relevant as they correspond to the levels of phenolics attainable in vivo after consumption of polyphenol-rich plant materials. For example, according to the accumulated research $[40,41]$, the maximal achievable concentration of plant phenolics in blood plasma can reach up to $5-10 \mu \mathrm{M}$, which generally corresponds to less than $5 \mu \mathrm{g} / \mathrm{mL}$. Taking into account the TPC levels evaluated for Cotoneaster fruits in the present study and the extraction efficiency (15-30\%, depending on the species), the levels of phenolics corresponding to the applied extract concentration of $1-5 \mu \mathrm{g} / \mathrm{mL}$ are about $0.13-1.25 \mu \mathrm{g} / \mathrm{mL}$ : well within the obtainable plasma range. This suggests that the protective activity of the Cotoneaster extracts towards $\mathrm{ONOO}^{-}$induced changes observed in vitro may translate to their positive in vivo effects.

The harmful influence of $\mathrm{ONOO}^{-}$is often associated with serious pathological consequences in many organs and systems of the human body. The nitration/oxidation of biomolecules such as enzymes, receptors, lipoproteins, fatty acids, or nucleic acids changes their function and may impair cellular signalization pathways, induce inflammatory responses, or even promote cell apoptosis $[38,39]$. In the case of the circulatory system, the negative effects of $\mathrm{ONOO}^{-}$result in a higher risk of cardiovascular disorders, such as stroke, myocardial infarction, or chronic heart failure [38], and are connected with the direct modifications of plasma proteins and lipids. For instance, the formation of 3-nitrotyrosine in fibrinogen might contribute to prothrombotic events in the blood coagulation cascade and fibrinolysis process [42], while thiol oxidation in platelet proteins leads to the inhibition of platelet function [43]. Additionally, oxidation of low-molecular-weight thiols, such as reduced glutathione, diminishes the endogenous antioxidant capacity of plasma and primes further oxidative damage in the system [38]. Similarly, lipid peroxidation initiated by $\mathrm{ONOO}^{-}$may propagate platelet aggregation [44], while peroxynitritemodified LDL binds with high affinity to macrophage scavenger receptors leading to foam cell formation, which represent a key early event in atherogenesis [38, 45]. The prevention of these processes partially explains the beneficial effects of Cotoneaster fruits reported by traditional medicine and might be regarded as a good strategy in prophylaxis of various cardiovascular complaints.

3.5. Cellular Safety. Due to its long tradition of consumption and application in folk medicine, the Cotoneaster fruits might be regarded as nontoxic. However, in the case of the concentrated extracts, a more detailed evaluation of their safety is required. Therefore, the next step of our research was a viability test on PMBCs which assessed the cytotoxicity of the extracts. After two, four, and six-hour incubation periods with the plant extracts at concentrations of 5, 25, and $50 \mu \mathrm{g} / \mathrm{mL}$, the viability of the extract-treated cells constituted $97.3-101.7 \%$ of that of the control (non-treated cells) and no statistically significant differences were found $(p>0.05)$ between the two values (Figure 5). These findings suggest that the Cotoneaster extracts do not have cytotoxic effects at these concentrations.

\section{Conclusion}

The current paper presents the first comprehensive phytochemical and activity study of Cotoneaster fruits. The fruits were found to possess distinct lipophilic and phenolic profiles, significant antioxidant activity in both chemical and biological models, noticeable inhibitory effects on the proinflammatory enzymes, and cellular safety. Hence, Cotoneaster fruits appear to be promising candidates for the production of pharma- and nutraceuticals associated with preventing and treating oxidative stress and inflammatory-related chronic diseases; they may also contribute to a balanced and varied diet comprising food rich in bioactive compounds. Furthermore, the protective effects against $\mathrm{ONOO}^{-}$-induced modifications in the plasma components, demonstrated by the polyphenolic fractions from the fruits of C. hjelmqvistii, C. zabelii, C. splendens, and C. bullatus at in vivo-relevant levels, may be considered as a molecular basis for the beneficial effects of Cotoneaster fruits within the cardiovascular system reported by traditional medicine. The biological activity demonstrated in the present study might therefore be a starting point of more extensive investigation on the nutritional 


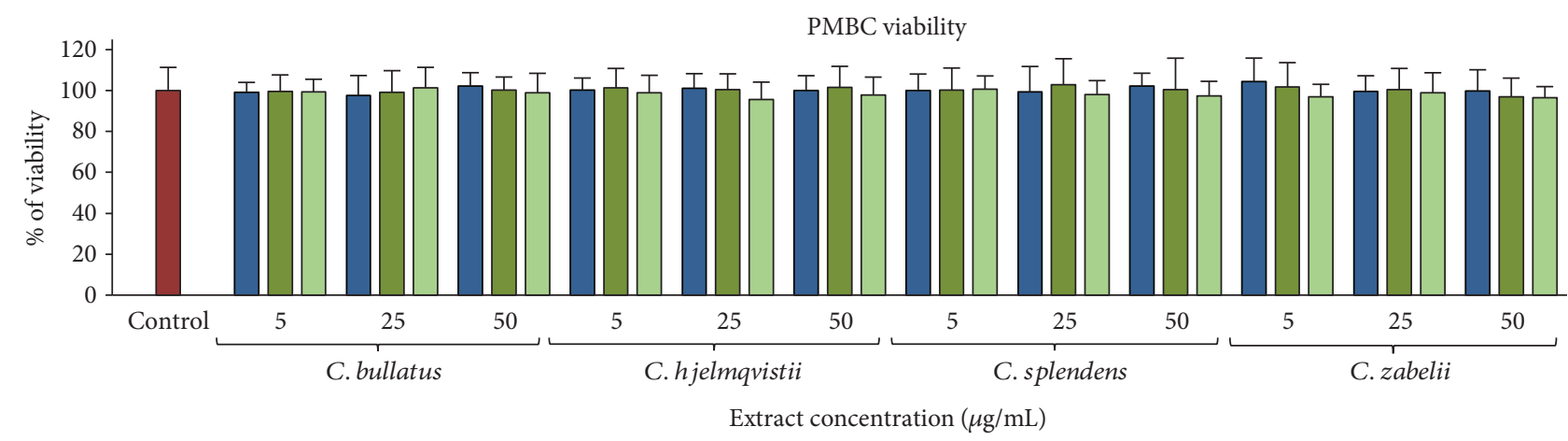

$\square 2 \mathrm{~h}$
$\square 4 \mathrm{~h}$
$\square 6 \mathrm{~h}$

FIgURE 5: Viability of peripheral blood mononuclear cells (PMBCs) after 2, 4, and $6 \mathrm{~h}$ incubation with the Cotoneaster fruit extracts at 5, 25, and $50 \mu \mathrm{g} / \mathrm{mL}$. Results are presented as means \pm SD $(n=14)$.

value and bioactivity of Cotoneaster fruits, including their effects in in vivo systems.

\section{Data Availability}

The data used to support the findings of this study are available from the corresponding author upon request.

\section{Conflicts of Interest}

The authors report no conflicts of interest.

\section{Acknowledgments}

This work was financially supported by the University of Lodz, Poland through Grant no. 506/1136 (the synthesis of peroxynitrite, $\mathrm{ONOO}^{-}$), the Medical University of Lodz, Poland through Grant no. 503/3-022-01/503-31-001 (the phytochemical and anti-inflammatory activity studies), and the National Science Centre, Poland through Grant no. 2017/01/X/NZ7/00520 (all other costs). The authors would like to thank the staff of the Botanical Garden in Lodz and the Forestry Experimental Station of the Warsaw University of Life Sciences in Rogow for providing and authenticating the plant material.

\section{References}

[1] H. Boeing, A. Bechthold, A. Bub et al., "Critical review: vegetables and fruit in the prevention of chronic diseases," European Journal of Nutrition, vol. 51, no. 6, pp. 637-663, 2012.

[2] O. Ogah, C. S. Watkins, B. E. Ubi, and N. C. Oraguzie, "Phenolic compounds in Rosaceae fruit and nut crops," Journal of Agricultural and Food Chemistry, vol. 62, no. 39, pp. 93699386, 2014.

[3] P. N. Denev, C. G. Kratchanov, M. Ciz, A. Lojek, and M. G. Kratchanova, "Bioavailability and antioxidant activity of black chokeberry (Aronia melanocarpa) polyphenols: in vitro and in vivo evidences and possible mechanisms of action: a review," Comprehensive Reviews in Food Science and Food Safety, vol. 11, no. 5, pp. 471-489, 2012.
[4] R. Raudonis, L. Raudonè, K. Gaivelyte,, P. Viškelis, and V. Janulis, "Phenolic and antioxidant profiles of rowan (Sorbus L.) fruits," Natural Product Research, vol. 28, no. 16, pp. 12311240, 2014.

[5] C. F. Zhao, S. Li, S. J. Li, G. H. Song, L. J. Yu, and H. Zhang, "Extraction optimization approach to improve accessibility of functional fraction based on combination of total polyphenol, chromatographic profiling and antioxidant activity evaluation: Pyracantha fortuneana fruit as an example," Journal of Functional Foods, vol. 5, no. 2, pp. 715-728, 2013.

[6] R. Pinacho, R. Y. Cavero, I. Astiasarán, D. Ansorena, and M. I. Calvo, "Phenolic compounds of blackthorn (Prunus spinosa L.) and influence of in vitro digestion on their antioxidant capacity," Journal of Functional Foods, vol. 19, pp. 49-62, 2015.

[7] J. M. Lee, H. Lee, S. B. Kang, and W. J. Park, "Fatty acid desaturases, polyunsaturated fatty acid regulation, and biotechnological advances," Nutrients, vol. 8, no. 1, p. 23, 2016.

[8] Z. Ovesná, A. Vachálková, K. Horváthová, and D. Tóthová, "Pentacyclic triterpenoic acids: new chemoprotective compounds. Minireview," Neoplasma, vol. 51, no. 5, pp. 327-333, 2004.

[9] F. Les, V. López, G. Caprioli et al., "Chemical constituents, radical scavenging activity and enzyme inhibitory capacity of fruits from Cotoneaster pannosus Franch," Food \& Function, vol. 8, no. 5, pp. 1775-1784, 2017.

[10] G.Zengin, A. Uysal, E. Gunes, and A. Aktumsek, "Survey of phytochemical composition and biological effects of three extracts from a wild plant (Cotoneaster nummularia Fisch. et Mey.): a potential source for functional food ingredients and drug formulations," PLoS One, vol. 9, no. 11, article e113527, 2014.

[11] G. Bisht, "Chemical constituents from the fruits of Cotoneaster microphylla Wall ex Lindl,” Asian Journal of Chemistry, vol. 7, pp. 455-456, 1995.

[12] A. Uysal, G. Zengin, A. Mollica et al., "Chemical and biological insights on Cotoneaster integerrimus: a new (-)-epicatechin source for food and medicinal applications," Phytomedicine, vol. 23, no. 10, pp. 979-988, 2016.

[13] W. A. Pryor, R. Cueto, X. Jin et al., "A practical method for preparing peroxynitrite solutions of low ionic strength and free of hydrogen peroxide," Free Radical Biology \& Medicine, vol. 18 , no. 1, pp. 75-83, 1995. 
[14] J. Nazaruk, A. Wajs-Bonikowska, and R. Bonikowski, "Components and antioxidant activity of fruits of Cirsium palustre and C. rivulare," Chemistry of Natural Compounds, vol. 48, pp. 9-10, 2012.

[15] T. T. Thanh, M. F. Vergnes, J. Kaloustian, T. F. El-Moselhy, M. J. Amiot-Carlin, and H. Portugal, "Effect of storage and heating on phytosterol concentrations in vegetable oils determined by GC/MS," Journal of the Science of Food and Agriculture, vol. 86, no. 2, pp. 220-225, 2006.

[16] M. A. Olszewska and P. Michel, "Antioxidant activity of inflorescences, leaves and fruits of three Sorbus species in relation to their polyphenolic composition," Natural Product Research, vol. 23, no. 16, pp. 1507-1521, 2009.

[17] P. Michel, A. Owczarek, M. Matczak et al., "Metabolite profiling of eastern teaberry (Gaultheria procumbens L.) lipophilic leaf extracts with hyaluronidase and lipoxygenase inhibitory activity," Molecules, vol. 22, no. 3, p. 412, 2017.

[18] M. A. Olszewska, A. Presler, and P. Michel, "Profiling of phenolic compounds and antioxidant activity of dry extracts from the selected Sorbus species," Molecules, vol. 17, no. 3, pp. 3093$3113,2012$.

[19] M. Matczak, A. Marchelak, P. Michel et al., "Sorbus domestica L. leaf extracts as functional products: phytochemical profiling, cellular safety, pro-inflammatory enzymes inhibition and protective effects against oxidative stress in vitro," Journal of Functional Foods, vol. 40, pp. 207-218, 2018.

[20] J. Kolodziejczyk-Czepas, P. Nowak, B. Wachowicz et al., "Antioxidant efficacy of Kalanchoe daigremontiana bufadienolide-rich fraction in blood plasma in vitro," Pharmaceutical Biology, vol. 54, no. 12, pp. 3182-3188, 2016.

[21] I. F. F. Benzie and J. J. Strain, "The ferric reducing ability of plasma (FRAP) as a measure of "antioxidant power": the FRAP assay," Analytical Biochemistry, vol. 239, no. 1, pp. 70-76, 1996.

[22] B. Matthaus and M. M. Özcan, "Fatty acid, tocopherol and squalene contents of Rosaceae seed oils," Botanical Studies, vol. 55 , no. 1 , p. $48,2014$.

[23] S. A. Mohamed, N. M. Sokkar, O. El-Gindi, Z. Y. Ali, and I. A. Alfishawy, "Phytoconstituents investigation, anti-diabetic and anti-dyslipidemic activities of Cotoneaster horizontalis Decne cultivated in Egypt," Life Science Journal, vol. 9, pp. 394-403, 2012.

[24] J. Lunn and H. E. Theobald, "The health effects of dietary unsaturated fatty acids," Nutrition Bulletin, vol. 31, no. 3, pp. 178-224, 2006.

[25] F. Anwar, R. Przybylski, M. Rudzinska, E. Gruczynska, and J. Bain, "Fatty acid, tocopherol and sterol compositions of Canadian prairie fruit seed lipids," Journal of the American Oil Chemists' Society, vol. 85, no. 10, pp. 953-959, 2008.

[26] P. Morales, I. C. F. R. Ferreira, A. M. Carvalho et al., "Wild edible fruits as a potential source of phytochemicals with capacity to inhibit lipid peroxidation," European Journal of Lipid Science and Technology, vol. 115, no. 2, pp. 176-185, 2013.

[27] E. Palme, A. R. Bilia, and I. Morelli, "Flavonols and isoflavones from Cotoneaster simonsii," Phytochemistry, vol. 42, no. 3, pp. 903-905, 1996.

[28] S. Khan, N. Riaz, Aziz-Ur-Rehman, N. Riaz, N. Afza, and A. Malik, "Isolation studies on Cotoneaster racemiflora," Journal of the Chemical Society of Pakistan, vol. 29, pp. 620-623, 2007.

[29] P. J. H. Jones and S. S. AbuMweis, "Phytosterols as functional food ingredients: linkages to cardiovascular disease and cancer," Current Opinion in Clinical Nutrition and Metabolic Care, vol. 12, no. 2, pp. 147-151, 2009.

[30] S. Saeidnia, A. Manayi, A. R. Gohari, and M. Abdollahi, "The story of beta-sitosterol-a review," European Journal of Medicinal Plants, vol. 4, no. 5, pp. 590-609, 2014.

[31] D. Vauzour, A. Rodriguez-Mateos, G. Corona, M. J. OrunaConcha, and J. P. E. Spencer, "Polyphenols and human health: prevention of disease and mechanisms of action," Nutrients, vol. 2, no. 11, pp. 1106-1131, 2010.

[32] M. Locatelli, G. Zengin, A. Uysal et al., "Multicomponent pattern and biological activities of seven Asphodeline taxa: potential sources of natural-functional ingredients for bioactive formulations," Journal of Enzyme Inhibition and Medicinal Chemistry, vol. 32, no. 1, pp. 60-67, 2017.

[33] G. Zengin, S. Nithiyanantham, M. Locatelli et al., "Screening of in vitro antioxidant and enzyme inhibitory activities of different extracts from two uninvestigated wild plants: Centranthus longiflorus subsp. longiflorus and Cerinthe minor subsp. Auriculata," European Journal of Integrative Medicine, vol. 8, no. 3, pp. 286-292, 2016

[34] A. Kicel, P. Michel, A. Owczarek et al., "Phenolic profile and antioxidant potential of leaves from selected Cotoneaster Medik. species," Molecules, vol. 21, no. 6, p. 688, 2016.

[35] R. Medzhitov, "Origin and physiological roles of inflammation,” Nature, vol. 454, no. 7203, pp. 428-435, 2008.

[36] S. T. Prigge, J. C. Boyington, M. Faig, K. S. Doctor, B. J. Gaffney, and L. M. Amzel, "Structure and mechanism of lipoxygenases,” Biochimie, vol. 79, no. 11, pp. 629-636, 1997.

[37] N. S. El-Safory, A. E. Fazary, and C. K. Lee, "Hyaluronidases, a group of glycosidases: current and future perspectives," Carbohydrate Polymers, vol. 81, no. 2, pp. 165-181, 2010.

[38] P. Pacher, J. S. Beckman, and L. Liaudet, "Nitric oxide and peroxynitrite in health and disease," Physiological Reviews, vol. 87, no. 1, pp. 315-424, 2007.

[39] C. Szabó, H. Ischiropoulos, and R. Radi, "Peroxynitrite: biochemistry, pathophysiology and development of therapeutics," Nature Reviews Drug Discovery, vol. 6, no. 8, pp. 662-680, 2007.

[40] S. Baba, N. Osakabe, M. Natsume, Y. Muto, T. Takizawa, and J. Terao, "In vivo comparison of the bioavailability of (+)-catechin, (-)-epicatechin and their mixture in orally administered rats," Journal of Nutrition, vol. 131, no. 11, pp. 2885-2891, 2001.

[41] C. Burak, V. Brüll, P. Langguth et al., "Higher plasma quercetin levels following oral administration of an onion skin extract compared with pure quercetin dihydrate in humans," European Journal of Nutrition, vol. 56, no. 1, pp. 343-353, 2017.

[42] J. Kolodziejczyk-Czepas, M. B. Ponczek, and P. Nowak, "Peroxynitrite and fibrinolytic system-the effects of peroxynitrite on t-PA-induced plasmin activity," International Journal of Biological Macromolecules, vol. 81, pp. 212-219, 2015.

[43] P. Nowak, B. Olas, E. Bald, R. Głowacki, and B. Wachowicz, "Peroxynitrite-induced changes of thiol groups in human blood platelets," Platelets, vol. 14, no. 6, pp. 375-379, 2003.

[44] C. Calzada, E. Vericel, and M. Lagarde, "Low concentrations of lipid hydroperoxides prime human platelet aggregation specifically via cyclo-oxygenase activation," Biochemical Journal, vol. 325, no. 2, pp. 495-500, 1997.

[45] N. Hogg, V. M. Darley-Usmar, A. Graham, and S. Moncada, "Peroxynitrite and atherosclerosis," Biochemical Society Transactions, vol. 21, no. 2, pp. 358-362, 1993. 


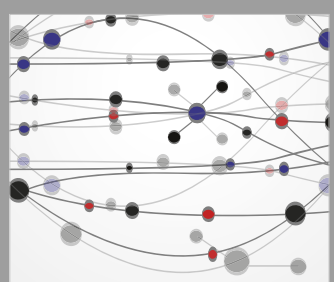

The Scientific World Journal
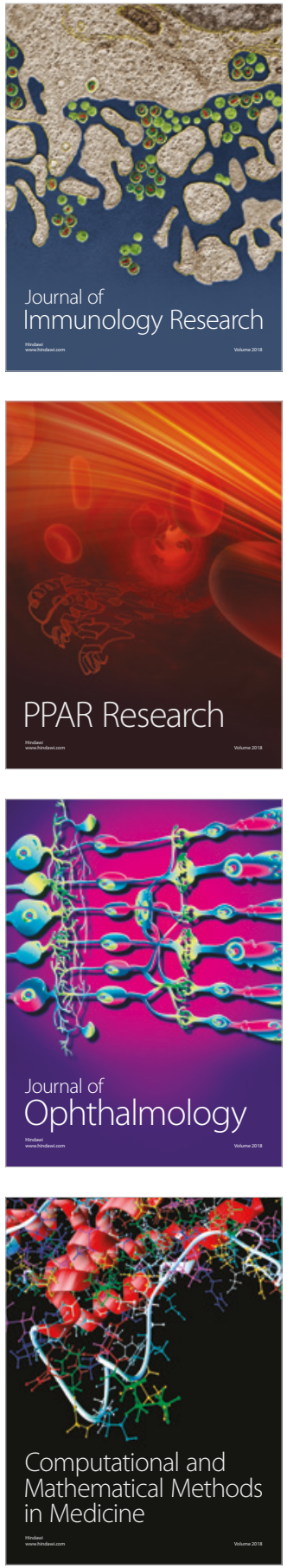

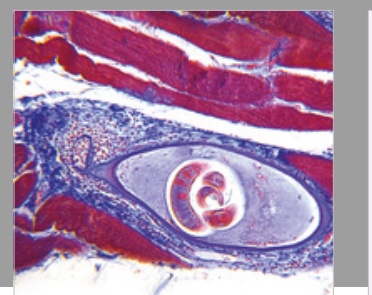

Gastroenterology Research and Practice

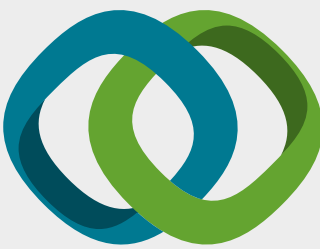

\section{Hindawi}

Submit your manuscripts at

www.hindawi.com
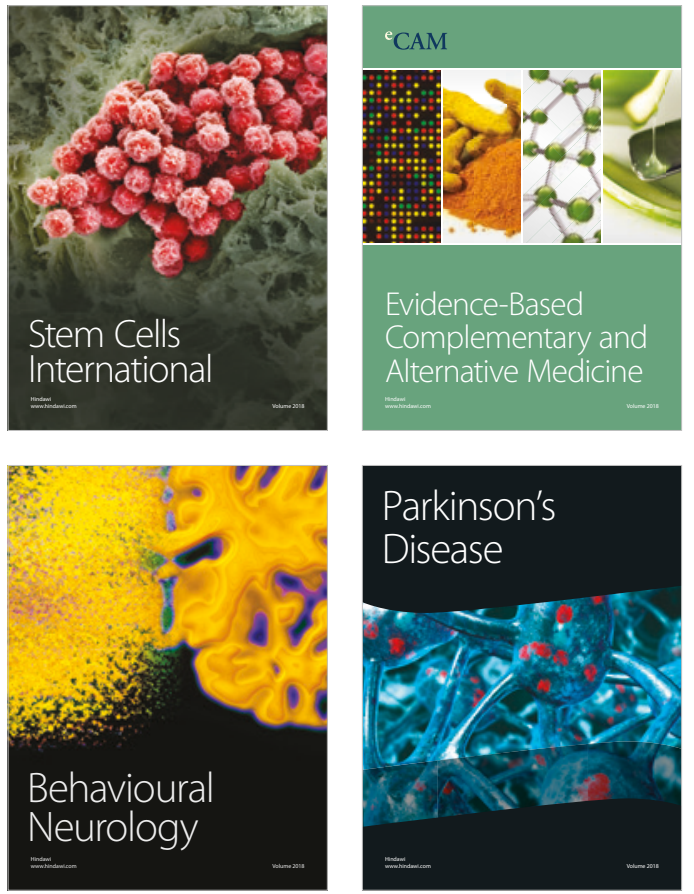

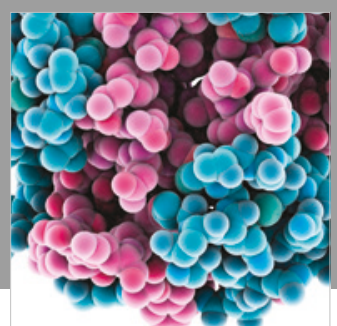

ournal of

Diabetes Research

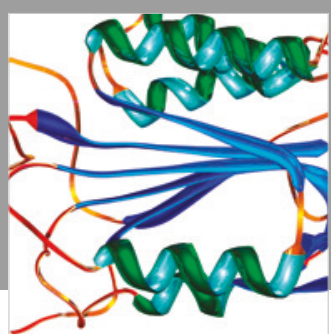

Disease Markers
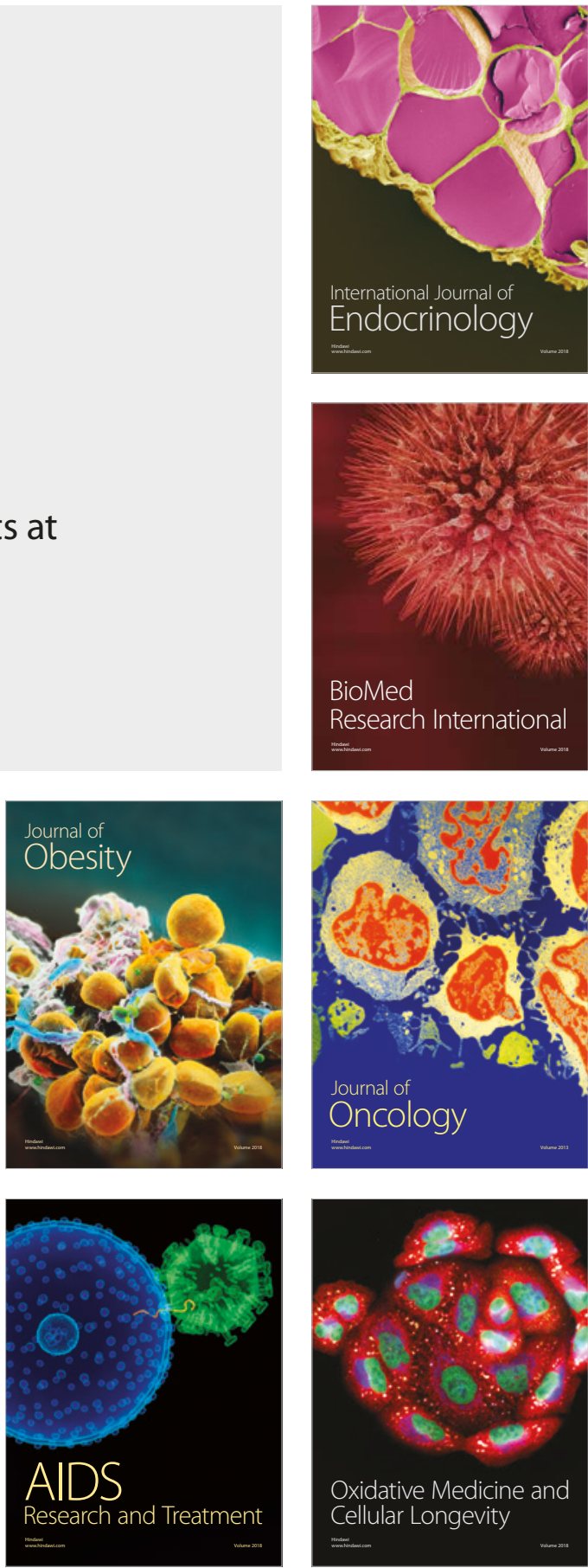